\title{
LA REPARACIÓN DIGNA CON PERSPECTIVA VICTIMOLÓGICA Y DE GÉNERO EN LOS DELITOS DE VIOLACIÓN SEXUAL COMETIDOS CONTRA LAS MUJERES, EN EL MARCO DEL DERECHO PENAL GUATEMALTECO
}

\author{
WORTHY REPARATION WITH VICTIMOLOGICAL AND GENDER PERSPECTIVE \\ ON CRIMES OF SEXUAL VIOLATION COMMITTED AGAINST WOMEN IN THE \\ LANDMARK OF GUATEMALA'S CRIMINAL LAW
}

\author{
REPARAÇÃO DIGNA COM PERSPECTIVA VITIMOLÓGICA E DE GÊNERO NOS \\ DELITOS DE VIOLAÇÃO SEXUAL COMETIDOS CONTRA AS MULHERES NO \\ MARCO DO DIREITO PENAL DA GUATEMALA
}

\author{
Xiomara Argentina Barillas Peláez \\ https://orcid.org/0000-0002-2859-1493 / xbarillas@renap.gov.gt \\ Universidad San Carlos - Guatemala
}

\begin{abstract}
RESUMO
O objetivo geral para essa investigação é determinar as diferentes formas de reparação digna à luz do direito internacional e nacional, pensadas em benefício das mulheres vítimas de sentenças condenatórias de delitos de violação cometidos na Guatemala, estabelecendo a numerosa normativa e jurisprudência internacional relativa aos direitos humanos e os critérios e standards de reparação digna aplicáveis a vítimas de crimes de violações sexuais contra mulheres. Isso leva a identificar os tipos de reparação digna ditadas nas resoluções judiciais e estabelecer as ações da vitimologia a favor das mulheres vítimas de violência sexual previstas nas sentenças condenatórias na questão da reparação digna, a qual constitui um mecanismo de ressarcimento social, econômico e moral, às mulheres vítimas de violência sexual como as vítimas colaterais que afrontam um processo penal na Guatemala.
\end{abstract}

Palavras-chave: Acesso à justiça; Direitos humanos das mulheres; Gênero; Reparação digna; Vitimologia.

\section{ABSTRACT}

The main objective of this investigation is to determine the different ways of worthy reparation in the perspective of national and international law, thought in benefit of women victims of condemnatory sentences about crimes of violation committed in Guatemala. Stablishing a large number of international laws and decisions about human rights, the criteria and standards of worthy reparation applicable to victims of sexual violation crimes against women. This takes on the identification of types of worthy reparation dictated on judicial decisions and the establishment of actions from victimology in favor of women victims of sexual violence predicted on condemnatory decisions about worthy reparation, which constitutes a mechanism of social, economic and moral compensation towards women victims of sexual violence as collateral victims that confront a criminal process in Guatemala.

Keywords: Access to justice; Women's human rights; Gender; Worthy reparation; Victimology.

\section{RESUMEN}

El objetivo general propuesto para esta investigación fue determinar las diferentes formas de reparación digna a la luz del derecho internacional y nacional, dictadas en beneficio de las víctimas mujeres en las sentencias condenatorias de delitos de violación cometidos en Guatemala. Estableciendo la numerosa normativa y jurisprudencia internacional relativa a derechos humanos, los criterios y estándares de reparación digna aplicables a víctimas de delito de violaciones sexuales contra mujeres; esto conlleva a identificar los tipos de reparación digna dictadas en las 
LA REPARACIÓN DIGNA CON PERSPECTIVA VICTIMOLÓGICA Y DE GÉNERO EN LOS DELITOS DE VIOLACIÓN SEXUAL COMETIDOS CONTRA LAS MUJERES, EN EL MARCO DEL DERECHO PENAL

resoluciones judiciales y, establecer las acciones victimológicas a favor de las mujeres víctimas de violencia sexual dictadas en las sentencias condenatorias en la audiencia de reparación digna, la cual constituye un mecanismo de resarcimiento social, económico y moral, a las víctimas mujeres de violación sexual como a las víctimas colaterales que afrontan un proceso penal en Guatemala.

Palabras clave: Acceso a la justicia; Derechos humanos de las mujeres; Género; Reparación digna; Victimología.

\section{SUMÁRIO}

INTRODUÇÃO; 1 ANÁLISIS DE LAS SENTENCIAS CONDENATORIAS POR EL DELITO DE VIOLACIÓN EN LOS TRIBUNALES DE FEMICIDIO Y OTRAS FORMAS DE VIOLENCIA CONTRA LA MUJER EN GUATEMALA; 1.1 La sentencia en la legislación guatemalteca; 1.2 La sentencia desde el análisis de la perspectiva de género; 2 ANÁLISIS COMPARATIVO DE LAS PRÁCTICAS IDENTIFICADAS EN SENTENCIAS CONDENATORIAS EN CUANTO A LA INCORPORACIÓN DE LA PERSPECTIVA DE GÉNERO, VICTIMOLOGÍA Y REPARACIÓN DIGNA; 3 LA REPARACIÓN DIGNA EN EL PROCESO PENAL GUATEMALTECO; 3.1 Consideraciones entorno a la reparación; 4 CLASIFICACIÓN DE LAS REPARACIONES; 4.1 Restitutio in integrum (plena restitución); 4.2 El daño; 5 LA REPARACIÓN DIGNA EN LA LEGISLACIÓN SUSTANTIVA GUATEMALTECA; 5.1 Código Penal; 5.2 Ley contra el Femicidio y Otras Formas de Violencia contra la Mujer; 5.3 Código Civil; 5.4 La Ley de Dignificación y Promoción Integral de la Mujer; 5.5 Ley Orgánica del Instituto para la Asistencia y Atención a la Víctima del Delito; 5.6 Audiencia de reparación digna en el Código Procesal Penal guatemalteco; CONCLUSÃO; REFERÊNCIAS.

\section{INTRODUÇÃO}

La protección y desarrollo de los derechos humanos en el ámbito nacional e internacional, ha permitido en la sociedad que sean reconocidos, respetados y promovidos de forma integral. En Guatemala y otros países de Latinoamérica, el control social ejercido por sectores sociales, políticos, religiosos, educativos y el sector justicia, no han permitido generar espacios en los cuales las mujeres desarrollen, ejerzan y accedan a sus derechos libremente, pues estos son limitados por los estereotipos, sexismos, controles a la sexualidad y la violencia en sus diversas manifestaciones que los propios operadores de justicia tienen. Esto conlleva que el acceso a la justicia sea limitado y que la justicia restaurativa en equidad sea casi una utopía, por ese frágil pero impenetrable techo de cristal.

Las víctimas de delito han sido tradicionalmente olvidadas tanto en el proceso penal, como en el diseño de las políticas de atención criminal, investigación y asistencia social, especialmente aquellas que proceden de los grupos vulnerables; entiéndase como vulnerables, aquellas personas que tienen disminuidas sus capacidades frente a eventuales lesiones, hechos que vulneren sus derechos primarios; esta fragilidad se asocia también a identificar a ciertas personas en un colectivo determinado que está en desventaja con otro. 
Las mujeres en diferentes épocas han sido sensibles a los ataques a su libertad, al derecho al voto, a la vida, entre otros derechos primarios, sufriendo daños físicos, psicológicos y sexuales aunados a la pérdida de sus bienes. Luego, en el acceso a la justicia donde se le somete a la víctima a un proceso de victimización secundaria por el aparato estatal, que no solventa las resultas del delito con la reparación integral que por derecho conlleva.

Tomando en consideración que la violencia sexual es uno de los grandes flagelos en la sociedad guatemalteca y que de acuerdo a las Estadísticas oficiales, este delito ocupa uno los diez más recurrentes; por ello, se procedió a realizar un análisis de la muestra de las sentencias condenatorias dictadas por el delito de violación sexual en contra de mujeres, mismas que evidencian en el cuerpo de la resolución que las acciones fiscales no permitieron ser atendidas las necesidades y preocupaciones de las víctimas, ya que, la intervención del agente fiscal en cuanto a la protección y atención integral fue reducida. Se demostró la falta de fundamentación y motivación de las y los juzgadores con respecto a la aplicación de la normativa nacional e internacional. Además, el desconocimiento de los operadores de justicia en la temática de la perspectiva de género y victimología es evidente, lo cual limita el real y efectivo acceso a la justicia de las víctimas con funcionarios indolentes y poco sensibilizados en la materia.

Es necesario, hacer valer el derecho a la reparación digna por medio de los órganos de justicia, pues constituye una herramienta indispensable en el mayor grado de desarrollo dentro del derecho internacional de los derechos humanos que se ha incorporado a la legislación nacional; se tiene a la reparación por finalidad de ubicar a la víctima de cualquier delito en una posición más o menos similar a la que se encontraba antes de la ocurrencia del hecho criminal, además, de restablecer en lo posible, aquellos derechos que fueron vulnerados.

\section{ANÁLISIS DE LAS SENTENCIAS CONDENATORIAS POR EL DELITO DE VIOLACIÓN EN LOS TRIBUNALES DE FEMICIDIO Y OTRAS FORMAS DE VIOLENCIA CONTRA LA MUJER EN GUATEMALA}

En Guatemala, las víctimas recorren un largo y penoso viacrucis, mismo que les hace recordar y revivir una y otra los hechos violentos, por la falta de un adecuado sistema de recopilación de información policial y fiscal. Aunado a ello el sistema de justicia en la etapa del juicio nuevamente revictimiza a las personas, exponiendo su integridad emocional y en algunos casos la física. 
Con el objeto de dar cumplimiento a lo estipulado en la Ley contra el Femicidio y otras formas de violencia contra la mujer y los compromisos internacionales, se incorporaron a la justicia penal órganos jurisdiccionales con enfoque de género, mediante la creación de juzgados de primera instancia penal y tribunales de sentencia en delitos de Femicidio y otras formas de violencia contra la mujer, las fiscalías de la mujer a nivel nacional y las Sistemas de atención integral para las mujeres, tanto en el Organismo Judicial como en el Ministerio Público; el acuerdo 01-2010 de la Corte Suprema de Justicia dan vida a los Juzgados y Tribunales de justicia especializada en Guatemala.

Es por ello que, en la emisión de una sentencia se debe solventar cada una de las cuestiones que hayan sido planteadas en el debate, derivado de una cuestión jurídica real y específica que decide el juzgador. El problema jurídico está definido por el tipo de proceso judicial, en el cual se enmarca la decisión de un ilícito cometido, en el marco de la aplicación del principio de legalidad. Debiendo observar los principios básicos de la justicia, independencia, honorabilidad, credibilidad, responsabilidad, transparencia, integridad, eficiencia, eficacia y efectividad, prudencia y respeto.

Para el análisis de las sentencias, y en el caso particular de los delitos de violencia sexual, es necesario determinar si cumplen con los requisitos de forma y de fondo, además si la resolución está fundamentada y motivada, conforme a la norma, la jurisprudencia de carácter nacional e internacional. Así mismo, determinar si se aplicó la teoría de género y los estándares internacionales en cuanto a la victimología desde el enfoque de derechos humanos. Se debe agregar que, la observancia, integración y aplicación de la normativa nacional e internacional en las sentencias debe realizarse de forma integral, concreta, adaptada al caso particular, a esto se le llama bloque de constitucionalidad.

\subsection{La sentencia en la legislación guatemalteca}

Sergio Alfaro define la sentencia como el "Acto judicial que resuelve hetero compositivamente el litigio ya procesado, mediante la aceptación que el juez hace de alguna de las encontradas posiciones mantenidas por los antagonistas luego de evaluar los medios confirmatorios de las afirmaciones efectuadas por el actor y de la aplicación particularizada al caso de una norma jurídica que preexiste en abstracto, con carácter general”. ${ }^{1}$

1 PONTIFICA UNIVERSIDAD CATÓLICA DE VALPARAíSO. Apuntes del estado. Derecho procesal. Pontifica Universidad Católica de Valparaíso (s.e.). Chile. 1998. p. 1. 
El juez al resolver debe satisfacer tres grandes y esenciales objetivos ${ }^{2}$ : La seguridad jurídica, que se divide en la forma racional (estructura) y los aspectos Jurídicos formales (fundamento de argumentos); Justicia y equidad y se divide a su vez en resultados razonables y de conformidad con principios; Eficacia que se traduce en la solución real del conflicto.

\subsection{La sentencia desde el análisis de la perspectiva de género}

Tomando en consideración que, para identificar en los hechos delictivos aquellas manifestaciones de violencia contra la mujer, es necesario conocer y reconocer este fenómeno de forma integral, ya que está basado en estereotipos, sexismos, prejuicios y otras formas de discriminación, que ha generado relaciones desiguales de poder entre hombres y mujeres. Por lo que es primordial en el análisis, detectar en las resoluciones judiciales si han incluido los estándares mínimos de derechos humanos especializados acordes a los convenios internacionales, doctrina y jurisprudencia que amplíe los términos de género, victimología y reparación digna, además que las y los juzgadores sean sensibles a la temática.

Una de las acciones para cumplir lo anterior, es generar en las y los operadores de justicia competencias que permitan adquirir conocimientos especializados en la teoría, perspectiva de género, victimología, además de carecer en lo personal de prejuicios y estereotipos de género, ya que al no ser sensibles al tema no permitirían visibilizar el problema de la violencia contra las mujeres y en este caso en particular la violencia sexual principalmente en las personas en situación de vulnerabilidad.

Los operadores de justicia deberán apegar las resoluciones judiciales a los estándares internacionales que en materia de derechos humanos se han ratificado por el Estado de Guatemala, criterio incorporado en el ordenamiento constitucional, por lo que al analizar las sentencias es menester tomar en consideración las modalidades en cuanto a reparación digna que la Corte Interamericana de Derechos Humanos considera.

Es imperante en aquellos delitos contra las mujeres, resolver y motivar las resoluciones con base en la teoría y perspectiva de género que permita ser sensible de las necesidades particulares de las mujeres, tal y como lo cita Gloria Ramírez citando a Alicia Elena Pérez Duarte, en cuanto a la incorporación de las herramientas género-sensitivas, "En contexto, la teoría de género permite: leer e interpretar una norma tomando en cuenta los principios

2 TRON PETIT, Jean Claude. Argumentación en el Amparo: esquema formal de los conceptos de violación y las sentencias de amparo. México: Editorial Porrúa, 2009. p. 13. 
ideológicos que la sustentan y, al mismo tiempo, la forma en que éstos afectan de manera diferenciada a quienes acuden a demandar justicia porque su metodología permite reconocer los símbolos y arquetipos que se encuentran en la trama del caso concreto que se pretende evaluar y reconocerlos en la escala de valores de las personas encargadas de procurar y administrar justicia". 3

El análisis de género debe identificar ${ }^{4}$ : La división laboral entre hombres y mujeres (trabajo productivo y trabajo reproductivo); El acceso y control sobre los recursos y beneficios; Las necesidades específicas (prácticas y estratégicas) de hombres y mujeres; Las limitaciones y oportunidades; La capacidad de organización de hombres y mujeres para promover la igualdad.

De acuerdo a lo anterior, es necesario incorporar la perspectiva de género y criterios victimológicos en la emisión de las sentencias cumpliendo con el mandato constitucional en cuanto a los principios de igualdad y no discriminación. Así como dar cumplimiento con los compromisos internacionales, en cuanto a lo regulado por la CEDAW al acceso real de la justicia en los procesos y resoluciones judiciales.

En la redacción de la sentencia se deberá observar estos indicadores:

a) El contexto en que se desarrollaron los hechos, las personas involucradas, las pericias técnico-científicas realizadas, las relaciones desiguales de poder entre la víctima y el sindicado, la edad, su desarrollo cultural y volitivo tomando en consideración su contexto social, las secuelas producto del hecho violento y la interrupción del proyecto de vida de la víctima, entre otras.

b) La utilización de un lenguaje no sexista, libre de estereotipos y sexismos.

c) El marco jurídico nacional e internacional, la doctrina y jurisprudencia que en la materia se aplique, garantizando con ello la fundamentación y motivación que por mandato legal se exige.

d) Determinar las estrategias jurídicas y sociales que garanticen los derechos fundamentales de las víctimas que conlleven la reparación digna.

e) Evidenciar en los medios de convicción y la valoración de la prueba producida en debate, aquellos estereotipos y sexismos detectados en los hechos, prueba científica, peritajes o cualquier otro presentado al Juzgador que perjudiquen a la víctima.

f) Reconocer y evidenciar en la sentencia los sesgos de género encontrados en la investigación criminal y durante el proceso penal que afectan a las mujeres víctimas.

\footnotetext{
${ }^{3}$ RAMÍREZ, Gloria. Op. Cit.

${ }^{4}$ LAGARDE, Marcela. Género y Feminismo. Madrid: J.C. Producción, 1996.
} 
ISSN 1981-3694

(DOI): $10.5902 / 1981369447921$

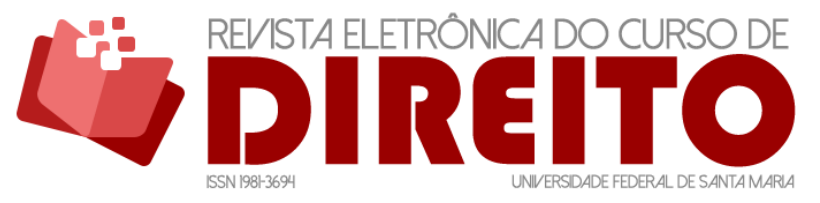

LA REPARACIÓN DIGNA CON PERSPECTIVA VICTIMOLÓGICA Y DE GENERO EN LOS DELITOS DE VIOLACION SEXUAL COMETIDOS CONTRA LAS MUJERES, EN EL MARCO DEL DERECHO PENAL GUATEMALTECO

XIOMARA ARGENTINA BARILLAS PELÁEZ

g) Determinar y valorar el impacto del delito en las mujeres víctimas, especialmente en el delito de violación, en los roles y responsabilidades laborales, familiares y sociales.

h) Eliminar aquellas acciones que tiendan a revictimizar a las mujeres víctimas y proporcionar medidas que promuevan la reparación digna de acuerdo a las secuelas del delito. 
XIOMARA ARGENTINA BARILLAS PELÁEZ

Tabla 1 - Análisis comparativo de las sentencias por el delito de violación

\begin{tabular}{|c|c|c|c|}
\hline Número de la sentencia & $\begin{array}{l}\text { Tipo de sentencia, delito } \\
\text { Pena }\end{array}$ & o elementos & $\begin{array}{l}\text { Normas aplicables comunes y } \\
\text { Normas con enfoque de género y/o } \\
\text { victimológicas }\end{array}$ \\
\hline $\begin{array}{l}\text { Carpeta judicial número } \\
\text { 03003-2015-01438 } \\
\text { Tribunal de sentencia } \\
\text { penal, narcoactividad y } \\
\text { delitos contra el Ambiente, } \\
\text { Sacatepéquez } \\
\text { Fecha } 16-10-2017\end{array}$ & $\begin{array}{l}\text { Condena por los delitos de: } \\
\text { Tres delitos de asesinato } \\
\text { Dos delitos de homicidio } \\
\text { Dos delitos de femicidio en grado } \\
\text { de tentativa } \\
\text { Violación con circunstancias } \\
\text { especiales de agravación } \\
125 \text { años de prision inconmutables } \\
\text { Pago de Q. } 330,600.00 \text { en calidad } \\
\text { de reparación. La Procuraduría } \\
\text { General de la Nación, velará que } \\
\text { los niños víctimas sean atendidos } \\
\text { en una institucion del Estado para } \\
\text { que se les otorgue tratamiento } \\
\text { psicológico. }\end{array}$ & $\begin{array}{l}\text { El autor del delito tuvo } \\
\text { relaciones sexuales de } \\
\text { forma violenta tanto física } \\
\text { y psicológica con la mujer } \\
\text { víctima de } 12 \text { años, a quien } \\
\text { la sustrajo de su hogar. La } \\
\text { víctima fue rescatada, } \\
\text { dichos actos eran grabados } \\
\text { en el celular del autor. }\end{array}$ & $\begin{array}{l}\text { Constitución Política de la República de } \\
\text { Guatemala; } \\
\text { Declaración Universal de los Derechos } \\
\text { Humanos; Convención Americana Sobre } \\
\text { Derechos Humanos; Código Penal; Código } \\
\text { Civil, Código Procesal Penal, Ley Electoral y } \\
\text { de Partidos Políticos; Código Civil, Ley del } \\
\text { Organismo Judicial } \\
\text { Ley contra el Femicidio y otras formas de } \\
\text { violencia contra las mujeres. }\end{array}$ \\
\hline $\begin{array}{l}\text { Carpeta judicial número } \\
05005-2015-00527 \text { (T.S. 43- } \\
2016 \text { Fecha 30-05-2016 } \\
\text { Tribunal de Sentencia } \\
\text { Penal de Delitos de } \\
\text { Femicidio y otras Formas } \\
\text { de Violencia Contra la } \\
\text { Mujer y Violencia Sexual } \\
\text { del departamento de } \\
\text { Escuintla. }\end{array}$ & $\begin{array}{l}\text { Violación con circunstancias } \\
\text { especiales de agravación } \\
\text { Pena: } 13 \text { años inconmutables }\end{array}$ & $\begin{array}{l}\text { Un hombre jaló a una niña y } \\
\text { la introdujo a su casa de } \\
\text { habitación en donde con } \\
\text { violencia física, psicológica } \\
\text { y aprovechándose de su } \\
\text { superioridad física en } \\
\text { contra XY, la llevó hasta su } \\
\text { habitación donde la despojó } \\
\text { de sus prendas de vestir y } \\
\text { abusó sexualmente de ella, } \\
\text { logrando su objetivo que } \\
\text { era el tener acceso carnal }\end{array}$ & $\begin{array}{l}\text { Constitución Política de la República de } \\
\text { Guatemala; } \\
\text { Declaración Universal de los Derechos } \\
\text { Humanos; Convención Americana Sobre } \\
\text { Derechos Humanos; Código Penal; Código } \\
\text { Civil, Código Procesal Penal, Ley Electoral y } \\
\text { de Partidos Políticos; Código Civil, Ley del } \\
\text { Organismo Judicial }\end{array}$ \\
\hline
\end{tabular}


LA REPARACIÓN DIGNA CON PERSPECTIVA VICTIMOLÓGICA Y DE GÉNERO EN LOS DELITOS DE VIOLACIÓN SEXUAL COMETIDOS CONTRA LAS MUJERES, EN EL MARCO DEL DERECHO PENAL

CONTRA LAS MUJERES, EN EL MARCO DEL DERECHO PENAL

GUATEMALTECO

\begin{tabular}{|c|c|c|c|}
\hline & & $\begin{array}{l}\text { vía vaginal con su víctima, a } \\
\text { quien después amenazó de } \\
\text { muerte si le contaba a su } \\
\text { familia }\end{array}$ & \\
\hline $\begin{array}{lr}\text { Carpeta judicial } & 13036- \\
2015-00149 & \text { (TSF.26-2017 } \\
\text { Tribunal de } & \text { Sentencia } \\
\text { Penal y Delitos } & \text { contra el } \\
\text { ambiente } & \text { del } \\
\text { departamento } & \text { de } \\
\text { Huehuetenango } & \end{array}$ & $\begin{array}{l}\text { Violación con agravación de la } \\
\text { pena y circunstancias especiales de } \\
\text { agravación } \\
\text { Pena: } 8 \text { años inconmutables }\end{array}$ & $\begin{array}{l}\text { Un hombre } X Y \text { de forma } \\
\text { violenta utilizando fuerza } \\
\text { física y psicológica violentó } \\
\text { sexualmente a una niña de } \\
13 \text { años. }\end{array}$ & $\begin{array}{l}\text { Constitución Política de la República de } \\
\text { Guatemala; } \\
\text { Declaración Universal de los Derechos } \\
\text { Humanos; Convención Americana Sobre } \\
\text { Derechos Humanos; Código Penal; Código } \\
\text { Civil, Código Procesal Penal, Ley Electoral y } \\
\text { de Partidos Políticos; Código Civil, Ley del } \\
\text { Organismo Judicial } \\
\text { Convención de los derechos del niño } \\
\text { Protección Integral de la niñez y } \\
\text { adolescencia } \\
\text { Convención Interamericana para prevenir, } \\
\text { sancionar y erradicar la Violencia contra la } \\
\text { CEDAW } \\
\text { Cien Reglas de Brasilia } \\
\text { Ley contra el femicidio y otras formas de } \\
\text { Violencia Contra la Mujer } \\
\text { Sentencias de la Corte Interamericana de } \\
\text { Derechos Humanos; Veliz Franco, Carpio } \\
\text { Nicolle, Myrna Mack, Panel Blanca }\end{array}$ \\
\hline $\begin{array}{l}\text { Número único de } \\
\text { expediente } \\
\text { 11003-2017-00226 } \\
\text { Proceso penal 130-2014 } \\
\text { Tribunal de sentencia } \\
\text { penal, narcoactividad y } \\
\text { delitos contra el Ambiente } \\
\text { de Retalhuleu } \\
11 \text { enero } 2018\end{array}$ & 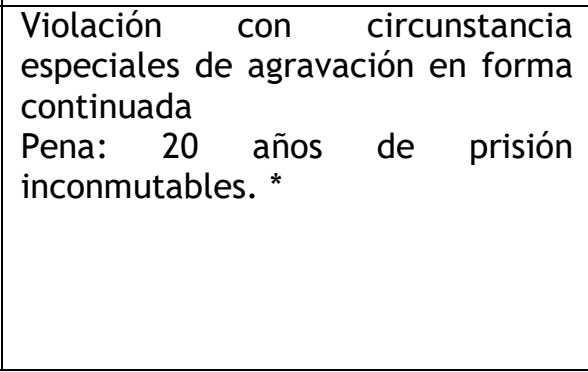 & $\begin{array}{l}\text { Niña víctima de } 10 \text { años que } \\
\text { refiere que el agresor le } \\
\text { bajaba la ropa e introducía } \\
\text { el pene en la boca y vagina, } \\
\text { la llevaba a un hotel y en la } \\
\text { vivienda de este con } \\
\text { violencia física y } \\
\text { psicológica. }\end{array}$ & $\begin{array}{l}\text { Constitución Política de la República de } \\
\text { Guatemala; } \\
\text { Declaración Universal de los Derechos } \\
\text { Humanos; Convención Americana Sobre } \\
\text { Derechos Humanos; Código Penal; Código } \\
\text { Civil, Código Procesal Penal, Ley Electoral y } \\
\text { de Partidos Políticos; Código Civil, Ley del } \\
\text { Organismo Judicial. }\end{array}$ \\
\hline
\end{tabular}

Revista Eletrônica do Curso de Direito da UFSM www.ufsm.br/revistadireito $\quad$ v. 15, n. 1 / 2020 e47921 
LA REPARACIÓN DIGNA CON PERSPECTIVA VICTIMOLÓGICA Y DE GÉNERO EN LOS DELITOS DE VIOLACIÓN SEXUAL COMETIDOS

CONTRA LAS MUJERES, EN EL MARCO DEL DERECHO PENAL GUATEMALTECO

\begin{tabular}{|c|c|c|c|}
\hline $\begin{array}{l}\text { Número único de } \\
\text { expediente } 02002-2016- \\
00021 \\
\text { Tribunal de Sentencia } \\
\text { Penal y Delitos contra el } \\
\text { Ambiente de El Progreso }\end{array}$ & $\begin{array}{l}\text { Violación con agravación de la } \\
\text { pena en forma continuada } \\
\text { Pena: } 24 \text { años inconmutables } \\
\text { Q.50000.00 de reparación digna }\end{array}$ & $\begin{array}{l}\text { Niña víctima de } 8 \text { años fue } \\
\text { violentada sexualmente } \\
\text { desde los tres años de edad } \\
\text { por el conviviente de la } \\
\text { madre. }\end{array}$ & $\begin{array}{l}\text { Constitución Política de la República de } \\
\text { Guatemala; } \\
\text { Declaración Universal de los Derechos } \\
\text { Humanos; Convención Americana Sobre } \\
\text { Derechos Humanos; Código Penal; Código } \\
\text { Civil, Código Procesal Penal, Ley Electoral y } \\
\text { de Partidos Políticos; Código Civil, Ley del } \\
\text { Organismo Judicial }\end{array}$ \\
\hline $\begin{array}{l}\text { Carpeta Judicial 01170- } \\
\text { 2015-00088 } \\
\text { Proceso penal 56-2016 } \\
\text { Tribunal de Sentencia } \\
\text { Penal de delitos de } \\
\text { Femicidio y otras formas } \\
\text { de violencia contra la } \\
\text { mujer y violencia sexual } \\
\text { del departamento de } \\
\text { Guatemala }\end{array}$ & $\begin{array}{l}\text { Violación con agravación de la } \\
\text { pena } \\
\text { Pena: } 13 \text { años con } 4 \text { meses } \\
\text { inconmutables } \\
\text { Se ordena al sistema de Atención } \\
\text { Integral del organismo Judicial } \\
\text { ubique un centro de asistencia } \\
\text { psicoterapéutica a la agraviada } \\
\text { El Ministerio Público renuncia al } \\
\text { plazo de tres días para la } \\
\text { audiencia de reparación y solicita } \\
\text { que se deje abierto a la vía civil. }\end{array}$ & $\begin{array}{l}\text { La voluntad del sujeto } \\
\text { activo utilizando violencia } \\
\text { física y psicológica tuvo } \\
\text { acceso carnal vía vaginal } \\
\text { con la agraviada, quien es } \\
\text { hija de su conviviente. La } \\
\text { víctima tiene la capacidad } \\
\text { volitiva y cognitiva } \\
\text { disminuida, y romo } \\
\text { consecuencia de la } \\
\text { violación la víctima tuvo } \\
\text { una hija. }\end{array}$ & $\begin{array}{l}\text { Constitución Política de la República de } \\
\text { Guatemala } \\
\text { Pacto internacional de derechos civiles y } \\
\text { políticos } \\
\text { Convención americana } \\
\text { Código penal } \\
\text { Código procesal penal } \\
\text { Ley del Organismo judicial } \\
\text { CEDAW } \\
\text { Belem Do Para }\end{array}$ \\
\hline
\end{tabular}

Fonte: organización propia. 
LA REPARACIÓN DIGNA CON PERSPECTIVA VICTIMOLÓGICA Y DE GÉNERO EN LOS DELITOS DE VIOLACION SEXUAL COMETIDOS CONTRA LAS MUJERES, EN EL MARCO DEL DERECHO PENAL

GUATEMALTECO

XIOMARA ARGENTINA BARILLAS PELÁEZ

Tomando en consideración lo estipulado en el documento "Análisis de Sentencias de Tribunales Penales sobre delitos de Femicidio y otras formas de Violencia contra la Mujer desde el enfoque de Derechos Humanos y de Género" ${ }^{5}$, realizado por la abogada Andrea Suárez Trueba, se ha analizado dos sentencias relacionadas al delito de violación cometidos contra mujeres. Los siguientes elementos sirven como criterios para evaluar el nivel de incorporación de los estándares internacionales sobre derechos humanos de las mujeres en el delito de violación en las sentencias:

Tabla 2 - Niveles de valoración en cuanto a los estándares internacionales

\begin{tabular}{|c|c|c|}
\hline $\begin{array}{l}\text { Niveles de valoración en cuanto a estandares } \\
\text { internacionales }\end{array}$ & $\begin{array}{l}\text { Sentencia } \\
\text { Delito (s) }\end{array}$ & $\begin{array}{l}\text { Sentencia } \\
\text { Delito (s) }\end{array}$ \\
\hline & 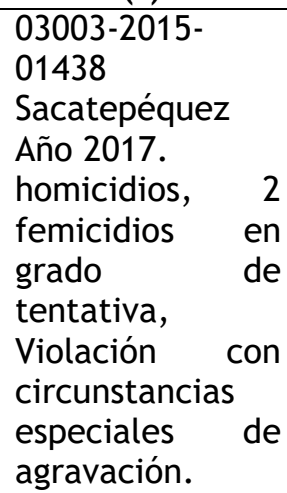 & $\begin{array}{l}02002-2006-00031 \\
\text { Violación con agravación } \\
\text { de la pena en forma } \\
\text { continuada. }\end{array}$ \\
\hline \multicolumn{3}{|l|}{ Nivel sólido } \\
\hline $\begin{array}{l}\text { Incorpora la mayoría de los estándares } \\
\text { internacionales pertinentes o apropiados para } \\
\text { el tema. }\end{array}$ & Ninguno & Ninguno \\
\hline $\begin{array}{l}\text { Explica de manera apropiada la razón por la } \\
\text { cual el estándar internacional es adecuado a la } \\
\text { situación concreta que se analiza. }\end{array}$ & Ninguno & Ninguno \\
\hline $\begin{array}{l}\text { Extrae del estándar internacional las } \\
\text { consecuencias jurídicas. }\end{array}$ & & Ninguno \\
\hline $\begin{array}{l}\text { Analiza la responsabilidad del Estado a la luz } \\
\text { de las obligaciones internacionales, utilizando } \\
\text { la jurisprudencia, recomendaciones u } \\
\text { observaciones generales de los mecanismos de } \\
\text { protección de derechos humanos. }\end{array}$ & Ninguno & Ninguno \\
\hline
\end{tabular}

${ }^{5}$ ORGANIZACIÓN DE LAS NACIONES UNIDAS. Oficina del alto comisionado para los Derechos Humanos en Guatemala. Herramienta para la incorporación del enfoque de derechos humanos y la perspectiva de género, en la elaboración de sentencias relativas a delitos de feminicidio y otras formas de violencia contra la 2015.2 mujer. $\quad 2$ Disponible https://www.ohchr.org/Documents/Issues/Women/WRGS/Herramienta_DHVSG_alta.pdf. Acceso el: 29 jun. 2020 
ISSN 1981-3694

(DOI): $10.5902 / 1981369447921$

LA REPARACIÓN DIGNA CON PERSPECTIVA VICTIMOLÓGICA Y DE GÉNERO EN LOS DELITOS DE VIOLACIÓN SEXUAL COMETIDOS CONTRA LAS MUJERES, EN EL MARCO DEL DERECHO PENAL

GUATEMALTECO

xom

\begin{tabular}{|l|l|l|}
\hline Nivel regular & & \\
\hline $\begin{array}{l}\text { Incorpora alguno de los estándares } \\
\text { internacionales pertinentes o apropiados para } \\
\text { el tema. }\end{array}$ & Ninguno & Ninguno \\
\hline $\begin{array}{l}\text { Provee algún tipo de explicación sobre la razón } \\
\text { por la cual el estándar internacional es } \\
\text { adecuado a la situación concreta que se } \\
\text { analiza. }\end{array}$ & Ninguno & Ninguno \\
\hline $\begin{array}{l}\text { Se limita a citar la jurisprudencia, } \\
\text { recomendaciones u observaciones generales de } \\
\text { órganos de tratados, sin explicar por qué es } \\
\text { pertinente en el caso concreto. }\end{array}$ & Ninguno & Ninguno \\
\hline Nivel limitado & & \\
\hline $\begin{array}{l}\text { Solamente cita los tratados internacionales, sin } \\
\text { desarrollar ninguno de los estándares en ellos } \\
\text { contenidos Si }\end{array}$ & & $\begin{array}{l}\text { En cuanto a la reparación } \\
\text { digna, se resuelve que la } \\
\text { mujer menor de edad } \\
\text { quedará a cargo de una }\end{array}$ \\
Casa Hogar. Además de \\
que la oficina de atencion \\
a la vicitma del Ministerio \\
Público deberá brindar \\
atencion psicologica y \\
como indemnizacion por el \\
daño moral o psicológico \\
Q.50,000.00
\end{tabular}

En las sentencias analizadas se evidencia la deficiencia en cuanto a la fundamentación en la normativa internacional, nacional y doctrina en cuanto a los derechos humanos de las mujeres y reparación digna correspondiente. Y como consecuencia la motivación de la misma en relación a la reparación digna es insuficiente para resarcir en el daño. 


\section{ANÁLISIS COMPARATIVO DE LAS PRÁCTICAS IDENTIFICADAS EN}

\section{SENTENCIAS CONDENATORIAS EN CUANTO A LA INCORPORACIÓN DE LA} PERSPECTIVA DE GÉNERO, VICTIMOLOGÍA Y REPARACIÓN DIGNA

Tabla 3 - Buenas prácticas sobre medidas de reparación en sentencias condenatórias

\begin{tabular}{|c|c|c|}
\hline Sentencia & $\begin{array}{l}\text { Tipos de } \\
\text { reparación }\end{array}$ & $\begin{array}{l}\text { Buenas prácticas identificadas sobre } \\
\text { medidas de reparación en sentencias } \\
\text { nacionales en casos de violación }\end{array}$ \\
\hline \multirow[t]{8}{*}{$\begin{array}{l}\text { Carpeta judicial. 05005-2016- } \\
00170 \\
\text { TS } 64-2016 \\
\text { Tribunal de Sentencia Penal de } \\
\text { Delitos de Femicidio y otras } \\
\text { Formas de Violencia Contra la } \\
\text { Mujer y Violencia Sexual del } \\
\text { Departamento de Escuintla. } \\
\text { Escuintla }\end{array}$} & $\begin{array}{l}\text { Delito } \\
\text { violacion } \\
16 \text { de } \\
\text { inconmutables. }\end{array}$ & \\
\hline & $\begin{array}{l}\text { Daño } \\
\text { inmaterial }\end{array}$ & \\
\hline & Daño moral & \\
\hline & $\begin{array}{l}\text { Daño } \\
\text { emergente }\end{array}$ & \\
\hline & $\begin{array}{l}\text { Medidas de } \\
\text { rehabilitacion } \\
\text { para las } \\
\text { víctimas y } \\
\text { víctimas } \\
\text { colaterales. }\end{array}$ & $\begin{array}{l}\text { "Resulta procedente como medida } \\
\text { victimológica que la víctima W.R.H.H., } \\
\text { reciba terapia y/o tratamiento psicológico, } \\
\text { por lo que se deberá referir a una institución } \\
\text { especializada, a efecto de que se integre a } \\
\text { un programa que le ayude, lo cual deberá } \\
\text { verificar y llevar el control respectivo, el } \\
\text { Sistema de Atención Integral de este } \\
\text { Tribunal, específicamente la persona } \\
\text { encargada de la presente carpeta judicial e } \\
\text { informar a esta Juzgadora inmediatamente } \\
\text { que la sentencia se encuentre firme." }\end{array}$ \\
\hline & $\begin{array}{l}\text { Restitución de } \\
\text { derecho. }\end{array}$ & \\
\hline & $\begin{array}{l}\text { Garantías de } \\
\text { no repetición. }\end{array}$ & \\
\hline & $\begin{array}{l}\text { En calidad de } \\
\text { reparacion } \\
\text { digna. }\end{array}$ & $\begin{array}{l}\text { Se accede a lo solicitado por el Querellante } \\
\text { Adhesivo en representación de la Víctima, } \\
\text { por lo cual el acusado debe pagar en } \\
\text { concepto de daño moral la cantidad de } \\
\text { Q.5000.00 }\end{array}$ \\
\hline
\end{tabular}


ISSN 1981-3694

(DOI): $10.5902 / 1981369447921$

LA REPARACIÓN DIGNA CON PERSPECTIVA VICTIMOLÓGICA Y DE GÉNERO EN LOS DELITOS DE VIOLACIÓN SEXUAL COMETIDOS CONTRA LAS MUJERES, EN EL MARCO DEL DERECHO PENAL

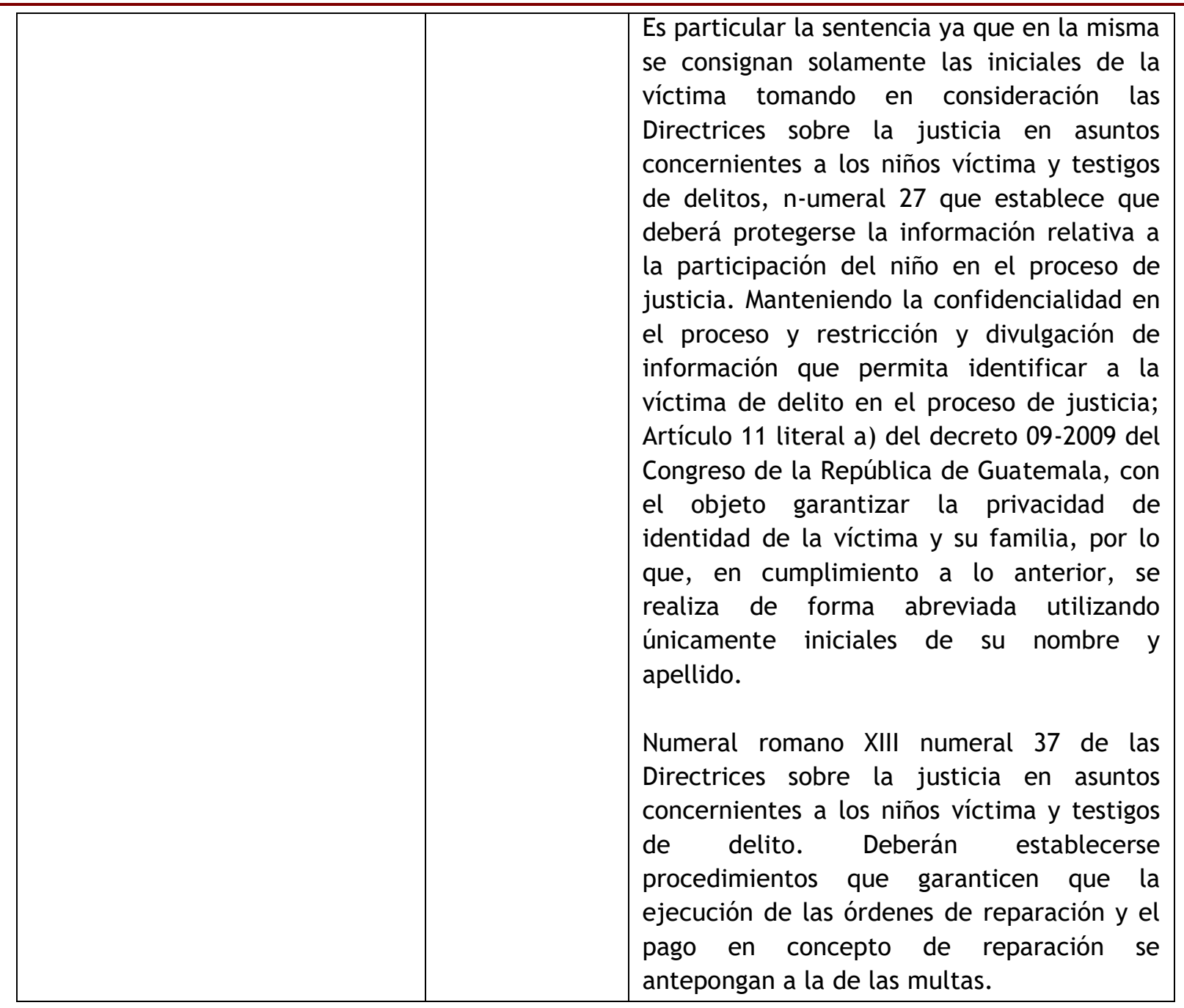


LA REPARACIÓN DIGNA CON PERSPECTIVA VICTIMOLÓGICA Y DE GÉNERO EN LOS DELITOS DE VIOLACIÓN SEXUAL COMETIDOS CONTRA LAS MUJERES, EN EL MARCO DEL DERECHO PENAL

Tabla 4 - Buenas prácticas sobre medidas de reparación en sentencias condenatorias

\begin{tabular}{|c|c|c|}
\hline SENTENCIA. & $\begin{array}{l}\text { Tipos de } \\
\text { reparación }\end{array}$ & $\begin{array}{l}\text { Buenas prácticas identificadas sobre } \\
\text { medidas de reparación en sentencias } \\
\text { nacionales en casos de violación }\end{array}$ \\
\hline \multirow[t]{8}{*}{$\begin{array}{c}\text { Carpeta judicial número } \\
\text { 05005-2015-00527 (T.S. 43- } \\
2016 \\
\text { Tribunal de Sentencia Penal } \\
\text { de Delitos de Femicidio y } \\
\text { otras Formas de Violencia } \\
\text { Contra la Mujer y Violencia } \\
\text { Sexual del Departamento de } \\
\text { Escuintla. }\end{array}$} & $\begin{array}{l}\text { Violación con } \\
\text { circunstancias } \\
\text { especiales de } \\
\text { agravación } \\
\text { Pena:13 años } \\
\text { inconmutables. }\end{array}$ & \\
\hline & Daño inmaterial. & \\
\hline & Daño moral. & 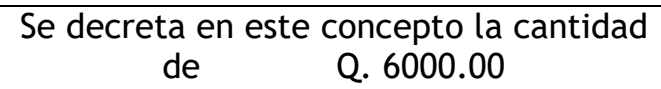 \\
\hline & Daño emergente. & \\
\hline & $\begin{array}{l}\text { Medidas de } \\
\text { rehabilitacion } \\
\text { para las víctimas } \\
\text { y víctimas } \\
\text { colaterales. }\end{array}$ & $\begin{array}{c}\text { Medidas victimológicas: como medida } \\
\text { victimológica, no a costa del procesado } \\
\text { sino a costa del Estado de Guatemala, se } \\
\text { ordena que la víctima. Reciba terapia y/o } \\
\text { tratamiento psicológico por el plazo que } \\
\text { el psicólogo tratante determine. Debe } \\
\text { coordinar el lugar más cercano a la } \\
\text { residencia. }\end{array}$ \\
\hline & $\begin{array}{l}\text { Restitución de } \\
\text { derecho. }\end{array}$ & \\
\hline & $\begin{array}{l}\text { Garantías de no } \\
\text { repetición. }\end{array}$ & \\
\hline & $\begin{array}{l}\text { En calidad de } \\
\text { reparacion. Digna }\end{array}$ & $\begin{array}{l}\text { En cuanto a la cantidad de seis mil } \\
\text { quetzales por pago de terapias } \\
\text { psicológicas que la agraviada debe recibir } \\
\text { según el dictamen pericial psicológico } \\
\text { relacionado, No ha lugar, en virtud que } \\
\text { no existe certeza, ni se ha acreditado, } \\
\text { cual es el pago de una terapia psicológica } \\
\text { en el departamento de Escuintla, por } \\
\text { medio de una especialista. }\end{array}$ \\
\hline
\end{tabular}


LA REPARACIÓN DIGNA CON PERSPECTIVA VICTIMOLÓGICA Y DE GÉNERO EN LOS DELITOS DE VIOLACIÓN SEXUAL COMETIDOS CONTRA LAS MUJERES, EN EL MARCO DEL DERECHO PENAL

Tabla 5 - Buenas prácticas sobre medidas de reparación en sentencias condenatorias

\begin{tabular}{|c|c|c|}
\hline SENTENCIA & $\begin{array}{l}\text { Tipos de } \\
\text { reparación }\end{array}$ & $\begin{array}{l}\text { Buenas prácticas identificadas sobre } \\
\text { medidas de reparación en sentencias } \\
\text { nacionales en casos de violación }\end{array}$ \\
\hline \multirow[t]{8}{*}{$\begin{array}{l}\text { Carpeta judicial número } \\
13036-2015-00149 \text { TSF26- } \\
2017 \\
\text { Tribunal de Sentencia Penal } \\
\text { de Delitos de Femicidio y } \\
\text { otras Formas de Violencia } \\
\text { Contra la Mujer y Violencia } \\
\text { Sexual del Departamento de } \\
\text { Huehuetenango. }\end{array}$} & 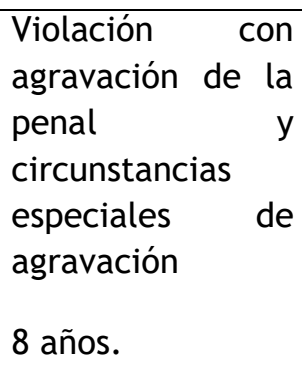 & \\
\hline & Daño inmaterial. & \\
\hline & Daño moral. & Se decreta la cantidad de Q. 5000.00 . \\
\hline & Daño emergente. & \\
\hline & $\begin{array}{l}\text { Medidas de } \\
\text { rehabilitacion } \\
\text { para las víctimas } \\
\text { y víctimas } \\
\text { colaterales. }\end{array}$ & $\begin{array}{l}\text { "Ordena coordinar con el Sistema de } \\
\text { Atención Integral del Organismo Judicial y } \\
\text { redes de derivacion del Ministerio } \\
\text { Público, a efecto brindar tratamiento } \\
\text { psicológico y tambien debe darsele } \\
\text { tratamiento al acusado para erradicar la } \\
\text { violencia contra la mujer". }\end{array}$ \\
\hline & $\begin{array}{l}\text { Restitución de } \\
\text { derecho. }\end{array}$ & \\
\hline & $\begin{array}{l}\text { Garantías de no } \\
\text { repetición. }\end{array}$ & \\
\hline & $\begin{array}{l}\text { En calidad de } \\
\text { reparacion digna. }\end{array}$ & $\begin{array}{l}\text { Q.5000.00 esta cantidad es la misma } \\
\text { consignada en la reparacion del daño } \\
\text { moral. }\end{array}$ \\
\hline
\end{tabular}


ISSN 1981-3694

(DOI): $10.5902 / 1981369447921$

LA REPARACIÓN DIGNA CON PERSPECTIVA VICTIMOLÓGICA Y DE GÉNERO EN LOS DELITOS DE VIOLACION SEXUAL COMETIDOS CONTRA LAS MUJERES, EN EL MARCO DEL DERECHO PENAL

Tabla 6 - Buenas prácticas sobre medidas de reparación en sentencias condenatorias

\begin{tabular}{|c|c|c|}
\hline SENTENCIA. & $\begin{array}{l}\text { Tipos de } \\
\text { reparación }\end{array}$ & $\begin{array}{l}\text { Buenas prácticas identificadas sobre } \\
\text { medidas de reparación en sentencias } \\
\text { nacionales en casos de violación }\end{array}$ \\
\hline \multirow[t]{8}{*}{$\begin{array}{l}\text { Número único de expediente } \\
\text { 11003-2017-00226 proceso } \\
\text { penal 130-2014 } \\
\text { Tribunal de sentencia penal, } \\
\text { narcoactividad y delitos } \\
\text { contra el ambiente de } \\
\text { Retalhuleu. }\end{array}$} & $\begin{array}{l}\begin{array}{l}\text { Violación con } \\
\text { circunstancia } \\
\text { especiales de } \\
\text { agravación en } \\
\text { forma continuada }\end{array} \\
20 \text { a los de prisión } \\
\text { inconmutables. }\end{array}$ & \\
\hline & Daño inmaterial. & \\
\hline & Daño moral. & \\
\hline & Daño emergente. & \\
\hline & $\begin{array}{lr}\text { Medidas } & \text { de } \\
\text { rehabilitacion para } \\
\text { las víctimas y } \\
\text { víctimas } \\
\text { colaterales. }\end{array}$ & $\begin{array}{l}\text { Se ordena la publicación de la sentencia } \\
\text { en páginas electrónicas Ministerio Público } \\
\text { y Organismo Judicial, garantizando la } \\
\text { privacidad de la víctima. }\end{array}$ \\
\hline & $\begin{array}{l}\text { Restitución } \quad \text { de } \\
\text { derecho. }\end{array}$ & \\
\hline & $\begin{array}{l}\text { Garantías de no } \\
\text { repetición. }\end{array}$ & \\
\hline & $\begin{array}{l}\text { En calidad de } \\
\text { reparacion digna. }\end{array}$ & $\begin{array}{l}\text { Con lugar la reparación digna por la } \\
\text { cantidad de Q. 27000.00. }\end{array}$ \\
\hline
\end{tabular}


LA REPARACIÓN DIGNA CON PERSPECTIVA VICTIMOLÓGICA Y DE GÉNERO EN LOS DELITOS DE VIOLACION SEXUAL COMETIDOS CONTRA LAS MUJERES, EN EL MARCO DEL DERECHO PENAL

Tabla 7 - Buenas prácticas sobre medidas de reparación en sentencias condenatorias

\begin{tabular}{|c|c|c|}
\hline SENTENCIA & $\begin{array}{l}\text { Tipos de } \\
\text { reparación }\end{array}$ & $\begin{array}{l}\text { Buenas prácticas identificadas sobre } \\
\text { medidas de reparación en sentencias } \\
\text { nacionales en casos de violación }\end{array}$ \\
\hline \multirow[t]{8}{*}{$\begin{array}{l}\text { Carpeta judicial número } \\
02002-2016-00021 \\
\text { Tribunal de Sentencia Penal } \\
\text { y delitos contra el Ambiente } \\
\text { del departamento de El } \\
\text { Progreso. }\end{array}$} & $\begin{array}{l}\text { Violación con } \\
\text { agravacion de la } \\
\text { pena en forma } \\
\text { continuada } \\
24 \text { años. }\end{array}$ & \\
\hline & Daño inmaterial & \\
\hline & Daño moral & $\begin{array}{l}\text { Por el daño moral y psicológico en agravio } \\
\text { de la víctima Q. } 50000.00\end{array}$ \\
\hline & Daño emergente & \\
\hline & $\begin{array}{l}\text { Medidas de } \\
\text { rehabilitacion } \\
\text { para las víctimas } \\
\text { y víctimas } \\
\text { colaterales }\end{array}$ & $\begin{array}{l}\text { Se ordena a la Oficina de Atención a la } \\
\text { víctima apoyo psicológico }\end{array}$ \\
\hline & $\begin{array}{l}\text { Restitución de } \\
\text { derecho }\end{array}$ & \\
\hline & $\begin{array}{l}\text { Garantías de no } \\
\text { repetición }\end{array}$ & \\
\hline & $\begin{array}{l}\text { En calidad de } \\
\text { reparacion digna }\end{array}$ & $\begin{array}{l}\text { Se ordena a la Directora de la Casa Hogar } \\
\text { Albergue en la localidad se le brinde } \\
\text { abrigo, vestido, alimentación, medicina y } \\
\text { lo necesario hasta que cumpla la mayoría } \\
\text { de edad. }\end{array}$ \\
\hline
\end{tabular}

En cada una de las sentencias, el objetivo era garantizar aquellas acciones tendientes a reparar el daño causado por el autor del delito en especial cuando la víctima sea una persona menor de edad. Por imperativo legal de debió responder a las necesidades especiales de las sobrevivientes de violación, con la finalidad que puedan reconstruir su proyecto de vida a partir 
ISSN 1981-3694

(DOI): $10.5902 / 1981369447921$

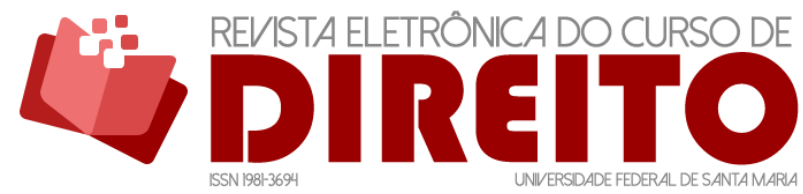

LA REPARACIÓN DIGNA CON PERSPECTIVA VICTIMOLÓGICA Y DE GEENERO EN LOS DELITOS DE VIOLACION SEXUAL COMETIDOS CONTRA LAS MUJERES, EN EL MARCO DEL DERECHO PENAL GUATEMALTECO

XIOMARA ARGENTINA BARILLAS PELÁEZ

de la reparación simbólica, económica y social, con un real acceso a la justicia, situación que al final de la sentencia no cubrió los aspectos anteriormente referidos.

Siendo que la incorporación de la normativa y jurisprudencia internacional es la gran ausente en el cuerpo de las sentencias analizados, esto permite concluir que la reparación digna no fue decretada de forma integral, real y efectiva; violando los derechos mínimos y elementales como la dignidad, patrimonio, proyecto de vida entre muchos de los derechos humanos de las mujeres que le fueron vulnerados.

Concluyendo, en la mayoría de las sentencias analizadas no se incorporó la perspectiva de género y victimología enfocada en los derechos humanos de las mujeres en casos de violencia sexual; y como consecuencia en la determinación de la reparación digna de forma integral en el caso concreto, comprobando que la o el Juzgador desconocía:

a) La forma de integrar en la sentencia el fenómeno estructural de la violencia que históricamente las mujeres han sufrido.

b) La legislación nacional, internacional, jurisprudencia y doctrina especializada en la temática de los derechos de las mujeres, victimología y reparación digna.

c) Lo actos constitutivos que conforman la misoginia, relaciones de poder desiguales, los prejuicios, discriminación y estereotipos que en los hechos dirimidos.

d) La utilización de un lenguaje incluyente.

Forma integral de abordar de las secuelas de las víctimas del delito de violación y por ende no se establecieron acciones propias para resarcir el daño producto del hecho ilícito.

Derivado del análisis de la sentencia y los argumentos anteriores se hace necesario determinar el marco conceptual y legal de lo que, en la doctrina, jurisprudencia, legislación nacional e internacional en cuanto al Derecho a la Reparación Digna integral que el Estado de Guatemala, a través de las instituciones del sector justicia está obligado a observar

\section{LA REPARACIÓN DIGNA EN EL PROCESO PENAL GUATEMALTECO}

Las víctimas de delito enfrentan distintas consecuencias de carácter físico, sicológico, sexual, patrimonial, sociales, de salud entre otras afectaciones. Esta victimización continúa en el transitar del proceso penal inclusive en la sentencia condenatoria, pues en algunos casos la víctima no es resarcida en el daño causado, causando sentimientos de impotencia, insatisfacción, entre otros. 
En ese sentido, el derecho de compensar, indemnizar, resarcir entre otros mecanismos, conviven en los distintos sistemas procesales en los que los Ministerios Públicos de cada país, deberán ser los encargados de representar a la víctima en el proceso penal.

En el sistema procesal guatemalteco, la víctima no había ocupado un lugar importante y activo, hasta que las recientes reformas penales propiciaron visibilizar los derechos de las mismas; a pesar de ello, no existen criterios y presupuestos claros que incluyan un resarcimiento integral, ya que en la mayoría de los casos no se logra una compensación adecuada a las pretensiones de las víctimas. Es por ello que las instituciones del sector justicia se han interesado en capacitar en temas afines a sus integrantes en las escuelas de capacitación en cumplimiento de las recomendaciones internacionales, a pesar de ello aun no es suficiente, ya que en el análisis de sentencias condenatorias las solicitudes de reparación digna, se evidencia que no cumplen con los estándares internacionales de reparación y menos cuentan con la perspectiva de género.

Tradicionalmente, el proceso penal concluye con la imposición de una pena, cuando se dicta una sentencia condenatoria, la víctima que en la mayoría de los casos queda desprotegida, pues no se le repara integralmente. Por ello, es necesario garantizar que la persona condenada repare el daño causado, con el objeto de que la víctima sea beneficiada tanto de forma material, moral y social.

Una de las herramientas jurídicas innovadoras en el sistema de justicia, en cuanto a la protección a la víctima es el Decreto 21-2016 del Congreso de la República de Guatemala, que da vida al Instituto para la Atención y Asistencia a la Víctima de Delito que tiene como finalidad garantizar los derechos de las víctimas proporcionando asesoría jurídica, psicológica y social, en apego a la Principios Fundamentales de Justicia para las Víctimas de Delitos y de Abuso de Poder.

\subsection{Consideraciones entorno a la reparación}

A continuación, se presentan aproximaciones a las distintas definiciones y criterios relacionados entorno a la reparación digna que por derecho tienen las víctimas que han sufrido las secuelas del delito. En ese sentido se presentan las siguientes:

Según el Diccionario de Ciencias Jurídicas, Políticas y Sociales de Manuel Osorio, se entiende por "Acción civil emergente del delito a la acción penal", y nos remite al significado de “Acción penal. La que se ejercita para establecer la responsabilidad criminal y, en su caso, la 
LA REPARACIÓN DIGNA CON PERSPECTIVA VICTIMOLÓGICA Y DE GEENERO EN LOS DELITOS DE VIOLACION SEXUAL COMETIDOS CONTRA LAS MUJERES, EN EL MARCO DEL DERECHO PENAL GUATEMALTECO

XIOMARA ARGENTINA BARILLAS PELÁEZ

civil, ocasionada por la comisión de un delito o falta. La determinación de quienes pueden ejercitar esta acción constituye uno de los temas más debatidos en derecho procesal y penal y resueltos por las diversas legislaciones de muy diversa manera. Como norma orientadora, puede afirmarse que la acción, está encomendada al Ministerio Fiscal, cuando se trata de delitos que afecten a la sociedad, otros delitos por su índole privada pueden ser accionados por la víctima o sus representantes. Dentro del procedimiento criminal, el perjudicado por el hecho delictuoso puede ejercitar la acción civil emergente del delito". ${ }^{6}$

Con el objeto de comprender el derecho a la reparación, se analizará entre otras, la clasificación de rubros reparables propuestos por el Relator Especial de Naciones Unidas, Theo van Boven, en el Proyecto de Principios y Directrices Básicos relativos a la reparación de violaciones flagrantes de los derechos humanos ${ }^{7}$ la misma puede presentarse bajo las siguientes formas: La restitución; La indemnización; Proyecto de vida; La satisfacción y las garantías de norepetición.

Otras corrientes han determinado la reparación desde la perspectiva de la justicia transicional, especialmente cuando se han abordado patrones y circunstancias vinculadas a violaciones graves y sistemáticas a los derechos humanos. En estos casos "la justicia transicional ${ }^{8}$ se ocupa que, en contextos de transición democrática y en situaciones donde se dio un conflicto interno, la sociedad exija y obtenga: La verdad de los hechos; Una reparación integral del daño, justicia; y La reconciliación nacional”.

La profesora venezolana Adriana Lander Osío, reúne en el documento Conceptualización sobre daños y reparaciones las consideraciones generales de las Sentencias de la Corte Interamericana de Derechos Humanos, vinculadas al tema de reparación digna que el Proyecto de Principios y Directrices Básicos refiere al término: Reparación, que se deriva etimológicamente de "reparar" deriva del latín reparare que, entre otras acepciones, significa

\footnotetext{
${ }^{6}$ Ossorio, Manuel. Diccionario de Ciencias Jurídicas, Políticas y Sociales. Guatemala: Datascan, 2006. p. 16-18

7 VAN BOVEN, Theo. Estudio relativo al derecho a la restitución, indemnización y rehabilitación a las víctimas de violaciones flagrantes de los derechos humanos y las libertades fundamentales. ONU, 2 de julio de 1993. Documento E/CN.4/Sub.2/1993/8. (Comisión de Derechos Humanos, $45^{\circ}$ Período de Sesiones de la Subcomisión de Prevención de Discriminaciones y Protección a las Minorías).

${ }^{8}$ La justicia transicional alude a las formas en que países que dejan atrás periodos de conflicto y represión utilizan para enfrentarse a violaciones de derechos humanos masivas o sistemáticas, de tal magnitud y gravedad que el sistema judicial convencional no puede darles una respuesta adecuada. La justicia transicional alude a las formas en que países que dejan atrás periodos de conflicto y represión utilizan para enfrentarse a violaciones de derechos humanos masivas o sistemáticas, de tal magnitud y gravedad que el sistema judicial convencional no puede darles una respuesta adecuada. Documento electrónico. ¿QUÉ es la justicia transicional? Centro Internacional para la Justicia Transicional (ICTJ). Disponible en: https://www.ictj.org/es/que-es-la-justicia-transicional. Acceso el: 29 jun. 2020.
} 
LA REPARACIÓN DIGNA CON PERSPECTIVA VICTIMOLÓGICA Y DE GÉNERO EN LOS DELITOS DE VIOLACIÓN SEXUAL COMETIDOS CONTRA LAS MUJERES, EN EL MARCO DEL DERECHO PENAL GUATEMALTECO

XIOMARA ARGENTINA BARILLAS PELÁEZ

"renovar, reconstruir, disponer de nuevo". Se entiende como "enmendar el menoscabo que ha padecido algo" o "dejar en buen estado algo que estaba roto o deteriorado".

Las reparaciones, como el término lo indica, "consisten en las medidas que tienden a hacer desaparecer los efectos de las violaciones cometidas. Su naturaleza y su monto dependen del daño ocasionado en los planos tanto material como inmaterial". 9

De acuerdo con el Diccionario jurídico elemental de Guillermo Cabanellas la responsabilidad es definida como "obligación de reparar y satisfacer por uno mismo o, en ocasiones especiales, por otro la pérdida causada, el mal inferido o el daño originado".

La Corte Interamericana de Derechos Humanos expresa que: "Las reparaciones, como el término lo indica, consisten en las medidas que tienden a hacer desaparecer los efectos de las violaciones cometidas. Su naturaleza y su monto dependen del daño ocasionado en los planos tanto material como inmaterial".

A partir de 1928, quedó establecido el derecho a la reparación como uno de los principios fundamentales del derecho internacional, siendo una regla consuetudinaria del derecho internacional, de aplicación en materia de derechos humanos y de derecho internacional humanitario. Así, el Tribunal Interamericano ${ }^{10}$ "ha sostenido que la reparación del daño ocasionado por la infracción de una obligación internacional consiste en la plena restitución restitutio in integrum ${ }^{11}$; lo que incluye el restablecimiento de la situación anterior y la reparación de las consecuencias que la infracción produjo y el pago de una indemnización como compensación por los daños patrimoniales y extrapatrimoniales incluyendo el daño moral".

\footnotetext{
${ }^{9}$ CORTE INTERAMERICANA DE DERECHOS HUMANOS. Caso Acevedo Jaramillo y otros Vs. Perú. Excepciones Preliminares, Fondo, Reparaciones y Costas. Sentencia de 7 de febrero de 2006. Serie C N. 144, párrafo 175. Disponible en: https://www.corteidh.or.cr/docs/casos/articulos/seriec_144_esp.pdf. Acceso el: 29 jun. 2020.

${ }^{10}$ MAC-GREGOR, Eduardo Ferrer; MÖLLER, Carlos María Pelayo. Deber de Adoptar Disposiciones de Derecho Interno. In: Christian Steiner; Patricia Uribe (Orgs.). Convención Americana sobre Derechos Humanos comentada. Bogotá, Colombia: Fundación Konrad Adenauer, Programa Estado de Derecho para Latinoamérica, 2014. Disponible en: https://www.corteidh.or.cr/tablas/30237.pdf. Acceso el: 29 jun. 2020. p. 69.

11 La restitutio in integrum en la antigua Roma: restablecimiento de la situación jurídica preexistente. En definitiva, con tal acto de autoridad, el Pretor no hacía otra cosa que "restablecer" la situación jurídica preexistente, como si el acto o negocio no hubiese tenido lugar: a esto se llama restitutio in integrum. Requisitos para con la restitución por entero en derecho romano. La restitución por entero no se concedía sino por causas graves, previstas unas veces en el Edicto o sometidas otras al prudente arbitrio del magistrado. Las principales fueron: la violencia, el dolo, el error, la ausencia justificada por cargo público, la cautividad de guerra, la minoría de edad, etc. RESTITUTIO in integrum en la antigua Roma. Derecho Romano, 14 de marzo de 2013. Disponible en:
} https://www.derechoromano.es/2013/03/restitutio-in-integrum.html. Acceso el: 29 jun. 2020. 
LA REPARACIÓN DIGNA CON PERSPECTIVA VICTIMOLÓGICA Y DE GENERO EN LOS DELITOS DE VIOLACION SEXUAL COMETIDOS CONTRA LAS MUJERES, EN EL MARCO DEL DERECHO PENAL GUATEMALTECO

XIOMARA ARGENTINA BARILLAS PELÁEZ

Para articular esta obligación, "la Corte $\mathrm{IDH}^{12}$ ha tomado como base lo dispuesto en el Artículo 63.1 de la Convención Americana ${ }^{13}$, y ha indicado que toda violación de una obligación internacional que haya producido daño comporta el deber de repararlo adecuadamente; y que esa disposición recoge una norma consuetudinaria que constituye uno de los principios fundamentales del Derecho Internacional contemporáneo sobre responsabilidad de un Estado".

Así, el Tribunal Interamericano ${ }^{14}$ "tiene competencia para ordenar tres distintos tipos de reparaciones, a saber: Garantizar el goce de los derechos y libertades previsto en el corpus iuris interamericano; Reparar las consecuencias de las violaciones cometidas por agentes privados o estatales; y Ordenar el pago de una indemnización justa. Lo anterior ha dado lugar a una gama muy importante de reparaciones, que incluyen la restitución, la compensación (donde también aparecen las costas judiciales), la rehabilitación, la satisfacción y las garantías de no repetición".

\section{CLASIFICACIÓN DE LAS REPARACIONES}

En cuanto a la clasificación de las reparaciones, puede tomarse la clasificación general propuesta por Víctor Rodríguez que las divide en tres: restitución (o plena restitución según la Corte), indemnización y satisfacción no patrimonial.

\subsection{Restitutio in integrum (plena restitución)}

La plena restitución se consigue al restablecer en cuanto sea posible el estado de las cosas en que se encontraban antes del daño. Esto se discute, debido que en muchos de los casos

12 La Corte Interamericana de Derechos Humanos (acrónimo: Corte IDH) es un órgano judicial de la Organización de los Estados Americanos (OEA) que goza de autonomía frente a los demás órganos de aquella y que tiene su sede en San José de Costa Rica, cuyo propósito es aplicar e interpretar la Convención Americana sobre Derechos Humanos y otros tratados de derechos humanos a los cuales se somete el llamado sistema interamericano de protección de derechos humanos.

${ }^{13}$ El Artículo 63.1 de la Convención Americana señala: "Cuando decida que hubo violación de un derecho o libertad protegidos en esta Convención, la Corte dispondrá que se garantice al lesionado en el goce de su derecho o libertad conculcados. Dispondrá, asimismo, si ello fuera procedente, que se reparen las consecuencias de la medida o situación que ha configurado la vulneración de esos derechos y el pago de una justa indemnización a la parte lesionada".

${ }^{14}$ MAC-GREGOR, Eduardo Ferrer; MÖLLER, Carlos María Pelayo. Deber de Adoptar Disposiciones de Derecho Interno. In: Christian Steiner; Patricia Uribe (Orgs.). Convención Americana sobre Derechos Humanos comentada. Bogotá, Colombia: Fundación Konrad Adenauer, Programa Estado de Derecho para Latinoamérica, 2014. Disponible en: https://www.corteidh.or.cr/tablas/30237.pdf. Acceso el: 29 jun. 2020. 
ISSN 1981-3694

(DOI): $10.5902 / 1981369447921$

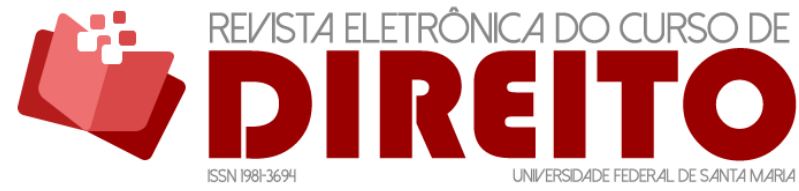

LA REPARACIÓN DIGNA CON PERSPECTIVA VICTIMOLÓGICA Y DE GÉNERO EN LOS DELITOS DE VIOLACIÓN SEXUAL COMETIDOS CONTRA LAS MUJERES, EN EL MARCO DEL DERECHO PENAL GUATEMALTECO

XIOMARA ARGENTINA BARILLAS PELÁEZ

y sobre todo en los delitos contra la vida es imposible restituir el daño, por lo que se deben buscar otras medidas tendientes a resarcir a las víctimas colaterales con medidas tendientes que aminoren los impactos del delito.

La jurisprudencia reciente de la Corte Interamericana, ha vinculado la reparación con la prevención, en los siguientes términos: "En lo que se refiere a la violación del derecho a la vida y otros derechos (libertad e integridad personales, garantías judiciales y protección judicial), por no ser posible la restitutio in integrum y dada la naturaleza del bien afectado, la reparación se realiza, inter alia, según la práctica jurisprudencial internacional, mediante una justa indemnización o compensación pecuniaria, a la cual deben sumarse las medidas positivas del Estado para conseguir que hechos lesivos como los del presente caso no se repitan".

La restitución completa de los derechos afectados (restitutio in integrum) está estipulada en el Principio 19 de los Principios y Directrices básicos sobre el derecho de las víctimas de violaciones de las normas internacionales de derechos humanos y del derecho internacional humanitario, a interponer recursos y obtener reparaciones, este señala que siempre que sea posible, ha de devolverse a la víctima a la situación anterior a la violación o afectación. Para ello se pueden implementar medidas, tales como, el restablecimiento de la libertad, el disfrute de los derechos humanos, la identidad, la vida familiar y la ciudadanía, el regreso a su residencia, la devolución de sus bienes, entre otros.

Con ello, el sistema de justicia, por medio de resoluciones judiciales debidamente fundamentadas y motivadas, podría garantizar de forma mínima e integral, que las víctimas de delito, especialmente en aquellos delitos graves, tengan una reparación acorde a las secuelas del delito, permitiendo restablecer y equilibrar su entorno, en algún momento la cotidianidad, el proyecto de vida, minimizando así el temor y la impunidad, por medio de un acto jurídico y simbólico a la vez.

De acuerdo con lo manifestado en las sentencias de la Corte Interamericana, la reparación integral dictada por el delito de violación permite la plena restitución de los derechos violados (restitutio in integrum), y se obtiene con el restablecimiento de la situación anterior a la violación, cuando ello es posible, adecuado y suficiente. La reparación integral permite generan medidas que brinden a las víctimas una satisfacción solamente pecuniaria, sino el reconocimiento de la responsabilidad internacional del Estado, por ejemplo, la publicación de las sentencias, las becas de estudio, monumentos conmemorativos, publicaciones académicas e investigaciones, entre otras restituciones. 
La reparación integral incluye también el pago de una indemnización que la Corte Interamericana ha resuelto como medida de compensación económica al dolor sufrido, de los perjuicios patrimoniales generados y de los gastos realizados como consecuencia de las violaciones y la búsqueda de amparo de los derechos. Esta incluye en su apreciación.

\subsection{El daño}

Puede definirse al daño ${ }^{15}$ como la "disminución o el perjuicio que experimentan los intereses patrimoniales, beneficios o bienes jurídicos de una persona. Una categorización general de los daños se clasifica en dos: daños materiales y daños inmateriales (o morales)".

Los daños materiales constituyen la disminución o el perjuicio que experimenta una persona en su patrimonio. De acuerdo con la Corte Interamericana de Derechos Humanos: “(...) el daño material supone la pérdida o detrimento de los ingresos de la víctima, los gastos efectuados con motivo de los hechos y las consecuencias de carácter pecuniario que tengan un nexo causal con los hechos del caso subjudice (...)" (Sentencia Hermanas Serrano Cruz vs. El Salvador, párrafo 150).

Al respecto, en derecho se han categorizado dos clases de daños materiales: pérdida de ingresos y el daño emergente que se explican de la manera siguiente:

a) Pérdida de ingresos (lucro cesante): tal como lo señala la expresión, está referido a los ingresos que la víctima ha dejado de recibir o la ganancia dejada de obtener y que hubiera recibido de no haberse producido el daño.

b) El daño emergente: es aquel que se sufre como resultado de haber realizado una prestación o inversión colateral. En cuanto a lo manifestado por la Corte Interamericana de Derechos Humanos, se entiende que: el daño emergente ${ }^{16}$ "es equivalente a los gastos directos e inmediatos que ha debido cubrir la víctima o sus representantes con ocasión del ilícito. Básicamente representa todos aquellos gastos que, en forma razonable y demostrable, hayan incurrido las víctimas con el objeto de reparar el ilícito, o bien, anular sus efectos. Inicialmente, en los procesos seguidos ante la Corte Interamericana fue un elemento básico el aportar los

15 Lander Osío, Adriana. Conceptualización sobre daños y reparaciones. Disponible en: https://biblioteca.iidh-jurisprudencia.ac.cr/index.php/documentos-en-espanol/verdad-justicia-yreparacion/1240-conceptualizacion-sobre-danos-y-reparaciones/file. Acceso el: 29 jun. 2020.

${ }_{16}$ Nash Rojas, Claudio. Las Reparaciones ante la Corte Interamericana de Derechos Humanos (1988 2007). 2. ed. Chile: Andros Impresores, 2009. p. 41. 
medios de prueba que acrediten la efectividad y cuantía de estos gastos, no siendo suficiente que estos sean simplemente invocados.

Los gastos por considerar pueden darse en tres etapas: Por actuaciones, gestiones y diligencias a nivel interno, con o sin asesoramiento de profesionales; Para actuar ante la Comisión Interamericana de Derechos Humanos; Para actuar ante la Corte Interamericana de Derechos Humanos".

La Corte Interamericana ha tratado una serie de medidas como parte de la "reparación del daño emergente:

a) Compensación por los gastos directos emanados de la violación sufrida;

b) Reparación por los salarios que deja de percibir la víctima en razón de la violación de los derechos convencionales, en caso de no reincorporación a las labores por despido sin fundamento, se ha determinado el pago de los salarios perdidos hasta la reincorporación o hasta la fecha de muerte, en caso de haber fallecido la víctima;

c) Compensar los gastos médicos y de otro tipo en que haya incurrido la víctima o sus familiares debido a la violación convencional.

d) Gastos en que hayan incurrido los familiares, específicamente, en la búsqueda de la víctima, en sus visitas, entierro, entre otros.

e) Reparación por las pérdidas patrimoniales de los familiares por motivos imputables al Estado, vinculados directamente con la violación de los derechos de la víctima; gastos médicos futuros que pueda involucrar un tratamiento vinculado con las violaciones convencionales".

El daño inmaterial consiste en una lesión a los sentimientos, al honor o la imagen; de acuerdo con la Corte Interamericana de Derechos Humanos: "El daño inmaterial puede comprender tanto los sufrimientos y las aflicciones causados a las víctimas directas y a sus allegados, el menoscabo de valores muy significativos para las personas, así como las alteraciones, de carácter no pecuniario, en las condiciones de existencia de la víctima o su familia. No siendo posible asignar al daño inmaterial un preciso equivalente monetario, solo puede, para los fines de la reparación integral a las víctimas, ser objeto de compensación (...)” (Sentencia Caesar vs. Trinidad y Tobago, de 11 de marzo de 2005, párrafo 125).

En ese sentido, el "Tribunal ha establecido que el daño inmaterial comprende tanto los sufrimientos y las aflicciones causadas a la víctima directa y a sus allegados, el menoscabo de valores muy significativos para las personas, así como las alteraciones, de carácter no 
LA REPARACIÓN DIGNA CON PERSPECTIVA VICTIMOLÓGICA Y DE GÉNERO EN LOS DELITOS DE VIOLACIÓN SEXUAL COMETIDOS CONTRA LAS MUJERES, EN EL MARCO DEL DERECHO PENAL GUATEMALTECO

XIOMARA ARGENTINA BARILLAS PELÁEZ

pecuniario, en las condiciones de existencia de la víctima o su familia. Corte IDH, Sentencia Caso Rosendo Cantú vs. México, párrafo 275".

Cabe destacar, en este sentido que, en la Sentencia de la CIDH del Caso Masacre de Plan de Sánchez v. Guatemala, la Corte consideró acreditada la pérdida de tradiciones y valores culturales, derivada de la muerte de los transmisores orales de ella y calificó la existencia de daño moral también a través de estos hechos. Masacre Plan de Sánchez v. Guatemala, 2004 Corte I.D.H. (ser. C) No.116. Esto constituye un reconocimiento a las víctimas desde sus necesidades, perspectiva y tradiciones culturales.

a) La indemnización: Cuando no se puede restituir, en su lugar se realiza una reparación, consistente en el pago de una suma de dinero con base en una estimación económica del daño que ha sufrido la víctima. Al pago de la suma de dinero se le denomina indemnización. Al respecto, cabe señalar que puede acordarse indemnización para reparar el daño material o el daño moral (compensación).

En cuanto a la indemnización por daño moral, la Corte Interamericana de Derechos Humanos ha señalado que: "No siendo posible asignar al daño inmaterial un preciso equivalente monetario, solo puede, para los fines de la reparación integral a las víctimas, ser objeto de compensación, y ello de dos maneras. En primer lugar, mediante el pago de una cantidad de dinero o la entrega de bienes o servicios apreciables en dinero, que el Tribunal determine en aplicación razonable del arbitrio judicial y en términos de equidad (...)" (Sentencia Caesar vs. Trinidad y Tobago, de 11 de marzo de 2005, párrafo 125).

Hay, también, las medidas de satisfacción y garantías de no repetición. La satisfacción puede referirse a "medidas que proveen reparación a la víctima de forma simbólica o representativa, pero que también tienen un impacto en la comunidad y el entorno social a lo interno del Estado, y repercusión pública". ${ }^{17}$ Se refieren a compensaciones no patrimoniales o no económicas, tal como señaló la Corte Interamericana de Derechos Humanos, el daño inmaterial puede ser compensado bien, por una indemnización o en segundo lugar: “(...) mediante la realización de actos u obras de alcance o repercusión públicos, tales como la transmisión de un mensaje de reprobación oficial a las violaciones de los derechos humanos de que se trata y de compromiso con los esfuerzos tendientes a que no vuelvan a ocurrir y que tengan como efecto, entre otros, el reconocimiento de la dignidad de la víctima (...)" (Sentencia Caesar vs. Trinidad y Tobago, de 11 de marzo de 2005, párrafo 125).

17 CORTE INTERAMERICANA DE DERECHOS HUMANOS. Caso de Acosta Calderón v. Ecuador. Fondo, Reparaciones y Costas. Sentencia de 24 de junio de 2005. Serie C, n. 129, 163-165. Disponible en: http://www.corteidh.or.cr/docs/casos/articulos/seriec_129_esp1.pdf. Acceso el: 29 jun. 2020. 
En la práctica de la Corte, las medidas de satisfacción que han sido propuestas y ordenadas son susceptibles de ser enmarcadas bajo cuatro categorías: determinación y reconocimiento de responsabilidad, disculpa, publicidad, y conmemoración.

El daño al proyecto de vida ${ }^{18}$, por su vez, "se asocia al concepto de realización personal, el poder conducir su vida y alcanzar el destino que se propone. En rigor, las opciones son la expresión y garantía de libertad. Por lo tanto, su cancelación o menoscaba, implican la reducción objetiva de la libertad y la pérdida de valor". ${ }^{19}$

Atiende a la realización integral de la persona afectada, considerando su vocación, aptitudes, circunstancias, potencialidades y aspiraciones, que le permiten fijarse razonablemente determinadas expectativas y acceder a ella.

La Corte Interamericana señala que, el mismo “constituye una noción diferente del daño emergente y del lucro cesante, debido a que no corresponde a la afectación patrimonial derivada directamente de los hechos como sucede con el daño emergente, ni tampoco se refiere a la pérdida de ingresos económicos futuros, cuantificables como sucede con el lucro cesante".

Cabe señalar que las víctimas de violencia sexual, especialmente aquellas víctimas del delito de violación sufren entre otras consecuencias la disminución de las oportunidades de estudio y/o, trabajo, que conlleva la ruptura del proyecto vital, limitando, deteriorando las condiciones socioeconómicas, y que en conjunto pueden derivar en secuelas de carácter psicológico.

La sumatoria de estos impactos que de forma directa e indirecta son recibidas en las víctimas de delito se definen y se deben contabilizar monetariamente, como lucro cesante; es decir, lo que la persona o la familia deja de percibir como consecuencia de la acción en contra de la víctima directa o indirecta.

La legislación guatemalteca, contempla el Proyecto de Vida, en la Ley Contra la Ley Contra la Violencia Sexual, Explotación y Trata de Personas decreto número 9-2009, el cual describe en el Artículo 1 inciso “i). Proyecto de vida: A las personas víctimas se les brindará medios de forma proporcional a sus necesidades para poder sustentar su proyecto de vida, buscando la erradicación de las causas de su victimización y el desarrollo de sus expectativas”.

18 CORTE INTERAMERICANA DE DERECHOS hUMANOS. Caso Loayza Tamayo Vs. Perú. Reparaciones y Costas. Sentencia de 27 de noviembre de 1998. Serie C No. 42, párr. 147. Disponible en: https://www.corteidh.or.cr/docs/casos/articulos/seriec_42_esp.pdf. Acceso el: 29 jun. 2020

${ }_{19}$ CALDERÓN GAMBOA, Jorge Francisco. Reparación del daño al proyecto de vida por violaciones a derechos humanos. México: Editorial Porrúa, 2005. 


\section{LA REPARACIÓN DIGNA EN LA LEGISLACIÓN SUSTANTIVA}

\section{GUATEMALTECA}

\subsection{Código Penal}

Artículo 112. "Toda persona responsable penalmente de un delito o falta, lo es también civilmente". ${ }^{20}$

Artículo 119 “La responsabilidad civil comprende: 10. La restitución. 2o. La reparación de los daños materiales o morales. 3o. La indemnización de perjuicios”. ${ }^{21}$

En cuanto a la indemnización de perjuicios, por compensación en dinero para reparar los daños y perjuicios que se ha causado al patrimonio de la víctima, la Corte Suprema de Justica señala “(...) la responsabilidad civil es subsidiaria de la penal y por tal razón a nadie puede condenarse el pago de la primera, sin haber sido declarado previamente, autor responsable de un delito determinado. Sentencia del 07 de enero de 1982, Gaceta de los Tribunales, Primer semestre 1982, $19-25 .^{22}$

Artículo 120. La restitución. La restitución deberá hacerse de la misma cosa, siempre que fuere posible, con abono de deterioros o menoscabo a juicio del tribunal y aunque la cosa se hallare en poder de un tercero que la haya adquirido legalmente, salvo su derecho a repetir contra quien corresponda. Esta última disposición no es aplicable cuando la cosa sea irreivindicable de poder del tercero, por haberla adquirido en la forma y con las condiciones que establecen las leyes civiles. ${ }^{23}$

Artículo 121. Reparación del daño material. La reparación se hará valorando la entidad del daño material, atendido al precio de la cosa y la afección del agraviado, si constare o pudiere apreciarse. ${ }^{24}$

20 GUATEMALA. Código Penal de Guatemala. Decreto $\mathrm{n}^{\circ} 17$ de 1973 . Disponible en: https://www.oas.org/dil/esp/Codigo_Penal_Guatemala.pdf. Acceso el: 29 jun. 2020.

21 GUATEMALA. Código Penal de Guatemala. Decreto $\mathrm{n}^{\circ} 17$ de 1973 . Disponible en: https://www.oas.org/dil/esp/Codigo_Penal_Guatemala.pdf. Acceso el: 29 jun. 2020.

22 Figueroa Sarti, Raúl. Código Penal, concordado y Anotado, con la exposición de motivos y la jurisprudencia constitucional y de la Corte Suprema. Pág. 112

23 GUATEMALA. Código Penal de Guatemala. Decreto $\mathrm{n}^{\circ} 17$ de 1973 . Disponible en: https://www.oas.org/dil/esp/Codigo_Penal_Guatemala.pdf. Acceso el: 29 jun. 2020.

24 GUATEMALA. Código Penal de Guatemala. Decreto $\mathrm{n}^{\circ} 17$ de 1973 . Disponible en: https://www.oas.org/dil/esp/Codigo_Penal_Guatemala.pdf. Acceso el: 29 jun. 2020. 


\subsection{Ley contra el Femicidio y Otras Formas de Violencia contra la Mujer}

El Artículo 3 preceptúa el “(...) h) Resarcimiento a la víctima: Se entenderá por resarcimiento el conjunto de medidas tendientes a aproximar la situación de la víctima al estado en que se encontraría de no haberse producido el hecho delictivo. El resarcimiento deberá caracterizarse por su integralidad y comprende además de indemnizaciones de carácter económico, todas aquellas medidas tendientes a dotar a la víctima de una reparación médica, psicológica, moral y social."25

El Artículo 11 preceptúa en cuanto al Resarcimiento a la víctima. "La reparación a la víctima será proporcional al daño causado y al grado de culpabilidad del autor del delito. En ningún caso implicará un enriquecimiento sin causa de la víctima. El resarcimiento podrá decretarse por los órganos de justicia que conozcan del caso concreto. Cuando la víctima haya fallecido, el derecho a la reparación se extiende a sus sucesores (...)". Fundamentándose en esta norma penal, para solicitar en los procesos penales, que culminen con una sentencia condenatoria, el pago de los daños y perjuicios materiales e inmateriales, ocasionados a la víctima por la comisión del hecho delictivo en su contra. ${ }^{26}$

El Artículo 12 indica que, "Responsabilidad del Estado. En cumplimiento a lo establecido en la Constitución Política de la República de Guatemala y en los convenios y tratados internacionales sobre derechos humanos aceptados y ratificados por el Estado de Guatemala, el Estado será solidariamente responsable por la acción u omisión en que incurran las funcionarias o funcionarios públicos que obstaculicen, retarden o nieguen el cumplimiento de las sanciones previstas en la presente ley, pudiendo ejercer contra éstas o éstos la acción de repetición si resultare condenado, sin perjuicio de las responsabilidades administrativas o civiles". ${ }^{27}$

${ }^{25}$ GUATEMALA. Ley contra el Femicidio y Otras Formas de Violencia contra la Mujer. Decreto $\mathrm{n}^{\circ} 22$ de 2008. Disponible https://www.oas.org/dil/esp/ley_contra_el_femicidio_y_otras_formas_de_violencia_contra_la_mujer_gu atemala.pdf. Acceso el: 29 jun. 2020.

${ }_{26}$ GUATEMALA. Ley contra el Femicidio y Otras Formas de Violencia contra la Mujer. Decreto $\mathrm{n}^{\circ} 22$ de 2008. https://www.oas.org/dil/esp/ley_contra_el_femicidio_y_otras_formas_de_violencia_contra_la_mujer_gu atemala.pdf. Acceso el: 29 jun. 2020.

27 GUATEMALA. Ley contra el Femicidio y Otras Formas de Violencia contra la Mujer. Decreto $n^{\circ} 22$ de 2008. https://www.oas.org/dil/esp/ley_contra_el_femicidio_y_otras_formas_de_violencia_contra_la_mujer_gu atemala.pdf. Acceso el: 29 jun. 2020. 


\subsection{Código Civil}

Artículo 1434. “Los daños, que consisten en las pérdidas que el acreedor sufre en su patrimonio, y los perjuicios, que son las ganancias lícitas que deja de percibir, deben ser consecuencia inmediata y directa de la contravención, ya sea que se hayan causado o que necesariamente deban causarse." Está inmerso dentro de los presupuestos de esta norma jurídica, explicar en qué consisten los daños y perjuicios, en el cual, está contenido la división que se hizo referencia al inicio del presente estudio, sobre el daño emergente y el lucro cesante, indicando que los daños son las pérdidas propiamente que se sufren por la comisión del delito, y los perjuicios son las ganancias que se dejan de percibir por haber sufrido ese daño. ${ }^{28}$

Artículo 1645. “Toda persona que cause daño o perjuicio a otra, sea intencionalmente, sea por descuido o Imprudencia, está obligada a repararlo, salvo que demuestre que el daño o perjuicio se produjo por culpa o negligencia inexcusable de la víctima."29

Artículo 1655. "Si el daño consiste en lesiones corporales, la víctima tiene derecho al reembolso de los gastos de curación y al pago de los daños o perjuicios que resulten de su incapacidad corporal, parcial o total para el trabajo, fijado por el juez en atención a las siguientes circunstancias: $1^{\circ}$. Edad, estado civil, oficio o profesión de la persona que hubiere sido afectada; $2^{\circ}$. Obligación de la víctima de alimentar a las personas que tengan derecho conforme a la ley; y $3^{\circ}$. Posibilidad y capacidad de pago de la parte obligada." 30

\subsection{La Ley de Dignificación y Promoción Integral de la Mujer}

En cuanto lo relacionado con la prevención y erradicación de la violencia contra la mujer y tomando en consideración la reparación del daño, el Artículo 18, señala que "Medidas específicas. d. Promoción de cambios normativos para que la mujer que haya sido sometida a violencia en cualquiera de sus formas y en cualquier ámbito, tengan acceso a medidas de

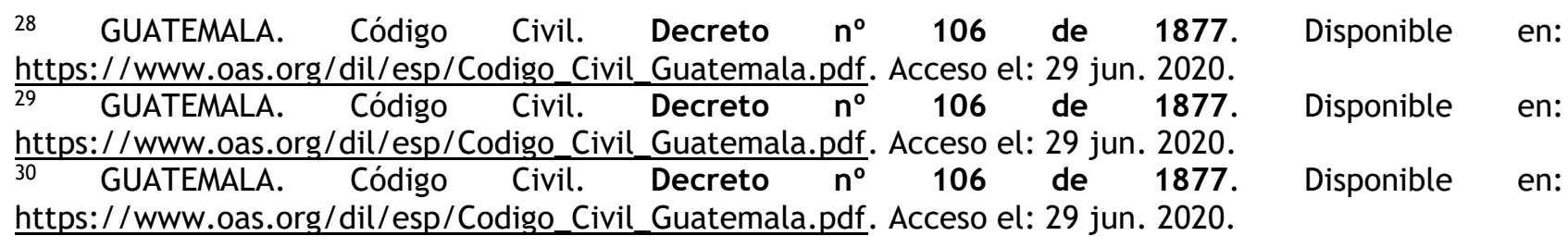


protección, juicio oportuno y mecanismos judiciales y administrativos que garanticen el resarcimiento, reparación del daño u otros medios de compensación". ${ }^{31}$

Cabe señalar que esta es una de las primeras normativas que señalan la reparación como un elemento indispensable en los programas de protección de los derechos humanos de las mujeres.

\subsection{Ley Orgánica del Instituto para la Asistencia y Atención a la Víctima del Delito}

En cuanto a la reparación del daño, estipula en el Artículo 29 que "Reparación digna. Es obligación del Instituto de la Víctima coadyuvar con el Ministerio Público en la garantía y defensa del derecho a la reparación digna de la víctima del delito, cuando ésta se haya constituido como querellante adhesivo. La reparación digna, además de lo establecido en el Código Procesal Penal, comprende medidas de restitución, rehabilitación, compensación, satisfacción y medidas de no repetición".32

\subsection{Audiencia de reparación digna en el Código Procesal Penal guatemalteco}

Posterior al pronunciamiento de la sentencia condenatoria y dictado el fallo en forma oral, el juzgador deberá convocar a las partes procesales a la audiencia de reparación. En la cual dará la palabra a la víctima, si se encuentra presente para que se pronuncie sobre si ejercitará la acción de reparación en ese momento, en caso afirmativo o en su ausencia convocará a la audiencia que se llevará a cabo el tercer día para el procedimiento de reparación digna. Las partes pueden renunciar al plazo de los tres días, pudiendo celebrarse la audiencia relacionada en cualquier momento dentro del plazo establecido.

En la audiencia, la víctima deberá acreditar el monto de la indemnización, la restitución y en su caso, los daños y perjuicios conforme a las reglas probatorias debiendo inmediatamente pronunciarse la decisión.

${ }^{31}$ GUATEMALA. Ley de Dignificación y Promoción integral de la Mujer. Decreto $n^{\circ} 7$ de 1999. Disponible en: http://www.sipi.siteal.iipe.unesco.org/sites/default/files/sipi_normativa/decreto_7-

99_ley_de_dignificacion_de_la_mujer_-_guatemala.pdf. Acceso el: 29 jun. 2020.

32 GUATEMALA. Ley Orgánica del Instituto Para la Asistencia y Atención a la Víctima del Delito. Decreto $\mathrm{n}^{\circ}$ 21 de 2016. Disponible en: https://leyes.infile.com/index.php?id=182\&id_publicacion=80435. Acceso el: 29 jun. 2020. 
LA REPARACIÓN DIGNA CON PERSPECTIVA VICTIMOLÓGICA Y DE GÉNERO EN LOS DELITOS DE VIOLACIÓN SEXUAL COMETIDOS CONTRA LAS MUJERES, EN EL MARCO DEL DERECHO PENAL

Con la decisión de reparación y la decisión sobre la responsabilidad penal y la pena se integra a la Sentencia. La responsabilidad civil será ejecutable hasta que la sentencia quede firme. ${ }^{33}$

El Artículo 124 refiere que el Derecho a la reparación digna. "La reparación a que tiene derecho la víctima comprende la restauración del derecho afectado por el hecho delictivo, que inicia desde reconocer a la víctima como persona con todas sus circunstancias como sujeto de derechos contra quien recayó la acción delictiva, hasta las alternativas disponibles para su reincorporación social a fin de disfrutar o hacer uso lo más pronto posible del derecho afectado, en la medida que tal reparación sea humanamente posible y, en su caso, la indemnización de los daños y perjuicios derivados de la comisión del delito; para el ejercicio de este derecho deben observarse las siguientes reglas:

1. La acción de reparación podrá ejercerse en el mismo proceso penal una vez dictada la sentencia condenatoria. El juez o tribunal que dicte la sentencia de condena, cuando exista víctima determinada, en el relato de la sentencia se convocará a los sujetos procesales y a la víctima o agraviado a la audiencia de reparación, la que se llevará a cabo al tercer día.

2. En la audiencia de reparación se deberá acreditar el monto de la indemnización, la restitución y, en su caso, los daños y perjuicios conforme a las reglas probatorias y, pronunciarse la decisión inmediatamente en la propia audiencia.

3. Con la decisión de reparación, y la previamente relatada responsabilidad penal y pena, se integra la sentencia escrita.

4. No obstante, lo anterior, en cualquier momento del proceso penal, la víctima o agraviado podrán solicitar al juez o tribunal competente, la adopción de medidas cautelares que permitan asegurar los bienes suficientes para cubrir el monto de la reparación.

5. La declaración de responsabilidad civil será ejecutable cuando la sentencia condenatoria quede firme". 34

33 En consonancia al Artículo 117 inciso “(...) e) en cuanto a los derechos de las víctimas indica que el recibir resarcimiento y/o reparación por los daños recibidos, constituye uno de los pilares que permitirán minimizar las secuelas del delito". Y en armonía con el principio de legalidad, la Corte Suprema de Justicia emitió el Acuerdo 19-2011, que establece en el artículo 4, que "la reforma al Código Procesal Penal, Decreto 7-2011, se aplicará para los procesos instruidos por delitos cometidos a partir del uno de julio de dos mil once". GuATEMALA. Código Procesal Penal. Decreto $\mathrm{n}^{\circ} 51$ de 1992. Disponible en: http://www.cicad.oas.org/fortalecimiento_institucional/legislations/PDF/GT/decreto_congresional_51 92_codigo_procesal_penal.pdf. Acesso el: 29 jun. 2020.

34 GUATEMALA. Código Procesal Penal. Decreto $\mathrm{n}^{\circ} 51$ de 1992 . Disponible en: http://www.cicad.oas.org/fortalecimiento_institucional/legislations/PDF/GT/decreto_congresional_51 92_codigo_procesal_penal.pdf. Acesso el: 29 jun. 2020. 
ISSN 1981-3694

(DOI): $10.5902 / 1981369447921$

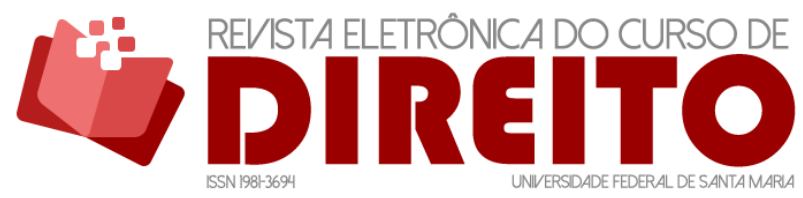

LA REPARACIÓN DIGNA CON PERSPECTIVA VICTIMOLÓGICA Y DE GÉNERO EN LOS DELITOS DE VIOLACIÓN SEXUAL COMETIDOS CONTRA LAS MUJERES, EN EL MARCO DEL DERECHO PENAL

GUATEMALTECO

XIOMARA ARGENTINA BARILLAS PELÁEZ

Si la acción reparadora no se hubiere ejercido en esta vía, queda a salvo el derecho de la víctima o agraviado a ejercerla en la vía civil. Por lo que los aspectos a considerar son:

a) Sentencia condenatoria.

b) Cuando exista víctima determinada, el juez convocará a la audiencia de reparación a los sujetos procesales, para llevarla a cabo al tercer día de emitida la audiencia condenatoria.

c) Es en la audiencia de reparación la cual de forma exclusiva se deberá acreditar la forma y el monto de la indemnización, la restitución y daños y perjuicios, causados a la víctima. Se deberán presentar los medios de convicción idóneos que emitan acreditar el daño.

d) La víctima o agraviado podrá solicitar al juez o tribunal competente, la adopción de medidas cautelares que permitan asegurar los bienes suficientes para cubrir el monto de la reparación.

e) La decisión de la reparación se integra a la sentencia de mérito.

f) Integrando la norma el Artículo 278 del CPP indica que podrá decretarse el embargo de bienes y las demás medidas de coerción para garantizar la multa o la reparación. ${ }^{35}$

Integrando la norma procesal, es primordial observar lo estipulado en el Artículo 338 del CPP, en cuanto a la actitud de las partes civiles, derivado que en dicha audiencia de deberá concretar detalladamente los daños emergentes del delito cuya reparación pretenden. Demostrarán mediante informes de trabajo social, psicológicos $u$ otros el importe aproximado de la indemnización o la forma de establecerla, se considerará los gastos de honorarios de los profesionales entre otros indicadores. La falta de cumplimiento de estas consideraciones será una forma de desistimiento de la acción. ${ }^{36}$

35 GUATEMALA. Código Procesal Penal. Decreto $\mathrm{n}^{\circ} 51$ de 1992 . Disponible en: http://www.cicad.oas.org/fortalecimiento_institucional/legislations/PDF/GT/decreto_congresional_5192_codigo_procesal_penal.pdf. Acesso el: 29 jun. 2020.

36 GUATEMALA. Código Procesal Penal. Decreto $\mathrm{n}^{\circ} 51$ de 1992. Disponible en: http://www.cicad.oas.org/fortalecimiento_institucional/legislations/PDF/GT/decreto_congresional_5192_codigo_procesal_penal.pdf. Acesso el: 29 jun. 2020. 


\section{CONCLUSIÓN}

La observancia de los derechos humanos de las mujeres en Guatemala, en cumplimiento de las recomendaciones internacionales, ha permitido generar herramientas técnicas y jurídicas, en la investigación criminal y en la legislación, promoviendo en el juzgamiento de las causas penales, la perspectiva de género con el objeto de que las mujeres se empoderen y denuncien todos aquellos hechos de violencia.

La violencia sexual contra las mujeres es un tema de derechos humanos de las mujeres, el cual ha sido integrado en algunas de las agendas públicas tanto a nivel internacional, regional y nacional. Destacando que, a pesar del avance normativo, no hay suficientes ni adecuados mecanismos de análisis, seguimiento, atención y reparación digna a las víctimas de delitos en general, mucho menos aquellas que han sufrido un ataque sexual.

En Guatemala, el control social ejercido por sectores sociales, políticos, religiosos, educativos y el sector justicia, no ha permitido generar espacios en los cuales las mujeres vivan una vida sin violencia, que permita desarrollar y ejercer sus derechos libremente, ya que estos son limitados por los estereotipos, controles a la sexualidad y la violencia en sus diversas manifestaciones. Esto conlleva que el acceso a la justicia sea limitado y que el acceso a la justicia restaurativa en equidad sea casi una utopía, por ese frágil pero impenetrable techo de cristal.

Se ha demostrado que existe la suficiente y pertinente normativa y jurisprudencia nacional e internacional, para la correcta aplicación de la justicia, en aquellos casos en los cuales las víctimas de violación exigen del Estado y sus instituciones la reparación digna que por derecho les corresponde. Esto conlleva a exigir como ciudadanas y ciudadanos que las sentencias sean debidamente fundamentadas y motivadas, a efecto de generar certeza jurídica en la aplicación de la norma que coadyuven a la construcción de un estado de Derecho, garante de los derechos humanos de la población.

La reparación digna es la compensación de las consecuencias del hecho delictivo por medio de emisión de la sentencia condenatoria, en la cual se comprueba el daño causado y las secuelas del hecho, al permitir dictar la reparación digna correspondiente, que no solamente incluye una indemnización pecuniaria sino también medidas tendientes a restablecer a la víctima, en lo posible, facilitando la atención integral médica, psicológica, social, educativa entre otras, que por derecho le corresponde. 


\section{REFERENCIAS}

CALDERÓN GAMBOA, Jorge Francisco. Reparación del daño al proyecto de vida por violaciones a derechos humanos. México: Editorial Porrúa, 2005.

CORTE INTERAMERICANA DE DERECHOS HUMANOS. Caso Acevedo Jaramillo y otros Vs. Perú. Excepciones Preliminares, Fondo, Reparaciones y Costas. Sentencia de 7 de febrero de 2006. Serie C N. 144, párrafo 175. Disponible en: https://www.corteidh.or.cr/docs/casos/articulos/seriec_144_esp.pdf. Acceso el: 29 jun. 2020.

CORTE INTERAMERICANA DE DERECHOS HUMANOS. Caso de Acosta Calderón v. Ecuador. Fondo, Reparaciones y Costas. Sentencia de 24 de junio de 2005. Serie C, n. 129, 163-165. Disponible en: http://www.corteidh.or.cr/docs/casos/articulos/seriec_129_esp1.pdf. Acceso el: 29 jun. 2020.

CORTE INTERAMERICANA DE DERECHOS HUMANOS. Caso Loayza Tamayo Vs. Perú. Reparaciones y Costas. Sentencia de 27 de noviembre de 1998. Serie C No. 42, párr. 147. Disponible en: https://www.corteidh.or.cr/docs/casos/articulos/seriec_42_esp.pdf. Acceso el: 29 jun. 2020.

GUATEMALA. Código Civil. Decreto n 106 de 1877. Disponible en: https://www.oas.org/dil/esp/Codigo_Civil_Guatemala.pdf. Acceso el: 29 jun. 2020

GUATEMALA. Código Penal de Guatemala. Decreto $\mathrm{n}^{\circ} 17$ de 1973. Disponible en: https://www.oas.org/dil/esp/Codigo_Penal_Guatemala.pdf. Acceso el: 29 jun. 2020.

GUATEMALA. Código Procesal Penal. Decreto $n^{\circ} 51$ de 1992. Disponible en: http://www.cicad.oas.org/fortalecimiento_institucional/legislations/PDF/GT/decreto_congresio nal_51-92_codigo_procesal_penal.pdf. Acesso el: 29 jun. 2020.

GUATEMALA. Ley contra el Femicidio y Otras Formas de Violencia contra la Mujer. Decreto $\mathrm{n}^{\circ} 22$ de 2008. Disponible en:

https://www.oas.org/dil/esp/ley_contra_el_femicidio_y_otras_formas_de_violencia_contra_la_ mujer_guatemala.pdf. Acceso el: 29 jun. 2020.

GUATEMALA. Ley de Dignificación y Promoción integral de la Mujer. Decreto $n^{\circ} 7$ de 1999. Disponible en:

http://www.sipi.siteal.iipe.unesco.org/sites/default/files/sipi_normativa/decreto_799_ley_de_dignificacion_de_la_mujer_-_guatemala.pdf. Acceso el: 29 jun. 2020.

GUATEMALA. Ley Orgánica del Instituto Para la Asistencia y Atención a la Víctima del Delito. Decreto $n^{\circ} 21$ de 2016. Disponible en: https: / / leyes.infile.com/index.php?id=182\&id_publicacion=80435. Acceso el: 29 jun. 2020.

LAGARDE, Marcela. Género y Feminismo. Madrid: J.C. Producción, 1996. 
LA REPARACIÓN DIGNA CON PERSPECTIVA VICTIMOLÓGICA Y DE GEENERO EN LOS DELITOS DE VIOLACION SEXUAL COMETIDOS CONTRA LAS MUJERES, EN EL MARCO DEL DERECHO PENAL

Lander Osío, Adriana. Conceptualización sobre daños y reparaciones. Disponible en: https: / / biblioteca.iidh-jurisprudencia.ac.cr/index.php/documentos-en-espanol/verdad-justiciay-reparacion/1240-conceptualizacion-sobre-danos-y-reparaciones/file. Acceso el: 29 jun. 2020.

MAC-GREGOR, Eduardo Ferrer; MÖLLER, Carlos María Pelayo. Deber de Adoptar Disposiciones de Derecho Interno. In: Christian Steiner; Patricia Uribe (Orgs.). Convención Americana sobre Derechos Humanos comentada. Bogotá, Colombia: Fundación Konrad Adenauer, Programa Estado de Derecho para Latinoamérica, 2014. Disponible en:

https://www.corteidh.or.cr/tablas/30237.pdf. Acceso el: 29 jun. 2020.

Nash Rojas, Claudio. Las Reparaciones ante la Corte Interamericana de Derechos Humanos (1988 - 2007). 2. ed. Chile: Andros Impresores, 2009

ORGANIZACIÓN DE LAS NACIONES UNIDAS. Oficina del alto comisionado para los Derechos Humanos en Guatemala. Herramienta para la incorporación del enfoque de derechos humanos y la perspectiva de género, en la elaboración de sentencias relativas a delitos de feminicidio y otras formas de violencia contra la mujer. 2015. Disponible en: https://www.ohchr.org/Documents/Issues/Women/WRGS/Herramienta_DHVSG_alta.pdf. Acceso el: 29 jun. 2020.

Ossorio, Manuel. Diccionario de Ciencias Jurídicas, Políticas y Sociales. Guatemala: Datascan, 2006.

PONTIFICA UNIVERSIDAD CATÓLICA DE VALPARAíSO. Apuntes del estado. Derecho procesal. Pontifica Universidad Católica de Valparaíso (s.e.). Chile. 1998.

¿QUÉ es la justicia transicional? Centro Internacional para la Justicia Transicional (ICTJ). Disponible en: https://www.ictj.org/es/que-es-la-justicia-transicional. Acceso el: 29 jun. 2020.

RESTITUTIO in integrum en la antigua Roma. Derecho Romano, 14 de marzo de 2013. Disponible en: https://www.derechoromano.es/2013/03/restitutio-in-integrum.html. Acceso el: 29 jun. 2020.

VAN BOVEN, Theo. Estudio relativo al derecho a la restitución, indemnización y rehabilitación a las víctimas de violaciones flagrantes de los derechos humanos y las libertades fundamentales. ONU, 2 de julio de 1993. Documento E/CN.4/Sub.2/1993/8. (Comisión de Derechos Humanos, $45^{\circ}$ Período de Sesiones de la Subcomisión de Prevención de Discriminaciones y Protección a las Minorías).

VERA SÁNCHEZ, Juan Sebastián. Cuatro mitos sobre la justicia retributiva como mecanismo de justicia transicional. American University International Law Review, v. 32, n. 2, 2015. Disponible en:

https://digitalcommons.wcl.american.edu/cgi/viewcontent.cgi?referer=\&httpsredir=1\&article=1 907\&context=auilr. Acceso el: 29 jun. 2020.

TRON PETIT, Jean Claude. Argumentación en el Amparo: esquema formal de los conceptos de violación y las sentencias de amparo. México: Editorial Porrúa, 2009. 
LA REPARACIÓN DIGNA CON PERSPECTIVA VICTIMOLÓGICA Y DE GÉNERO EN LOS DELITOS DE VIOLACIÓN SEXUAL COMETIDOS CONTRA LAS MUJERES, EN EL MARCO DEL DERECHO PENAL

\section{COMO FAZER REFERÊNCIA AO ARTIGO (ABNT):}

PELÁEZ, Xiomara Argentina Barillas. A reparação digna com perspectiva vitimológica e de gênero nos delitos de violação sexual cometidos contra as mulheres no marco do direito penal da Guatemala. Revista Eletrônica do Curso de Direito da UFSM, Santa Maria, RS, v. 15, n. 1, e47921, jan./abr. 2020. ISSN 1981-3694. DOI: http://dx.doi.org/10.5902/1981369447921. Disponível em:

https://periodicos.ufsm.br/revistadireito/article/view/47921 Acesso em: dia mês. ano.

Direitos autorais 2020 Revista Eletrônica do Curso de Direito da UFSM

Editores responsáveis: Rafael Santos de Oliveira e Angela Araujo da Silveira Espindola

Esta obra está licenciada com uma Licença Creative Commons Atribuição-NãoComercial-SemDerivações 4.0 Internacional.

\section{SOBRE O AUTOR}

\section{XIOMARA ARGENTINA BARILLAS PELÁEZ}

Profesora Doctora en la Universidad San Carlos, en Guatemala. 